\title{
Residential Ventilation Standards Scoping Study
}

\author{
T. E. McKone and M. H. Sherman
}

Prepared in Support of

Task Order No. 12 for

LBNL Technical Assistance for PIER ${ }^{1}$

CIEE Blanket Award Number C-02-01

Lawrence Berkeley National Laboratory Report Number: LBNL-53800

\section{OVERVIEW}

This document presents the findings of a scoping study commissioned by the Public Interest Energy Research (PIER) program of the California Energy Commission to determine what research is necessary to develop new residential ventilation requirements for California. This study is one of three companion efforts needed to complete the job of determining the ventilation needs of California residences, determining the bases for setting residential ventilation requirements, and determining appropriate ventilation technologies to meet these needs and requirements in an energy efficient manner.

Rather than providing research results, this scoping study identifies important research questions along with the level of effort necessary to address these questions and the costs, risks, and benefits of pursuing alternative research questions. In approaching these questions and corresponding levels of effort, feasibility and timing were important considerations. The Commission has specified Summer 2005 as the latest date for completing this research in time to update the 2008 version of California's Energy Code (Title 24)

\footnotetext{
${ }^{1}$ This report describes work supported by the California Energy Commission through the Public Interest Energy Research program under contract no. 500-98-033, and by the Assistant Secretary for Energy Efficiency and Renewable Energy, Office of Building Technology, State and Community Programs, Office of Building Research and Standards, of the U.S. Department of Energy under contract no. DE-AC03-76SF00098.
} 


\section{TABLE OF CONTENTS}

OVERVIEW.

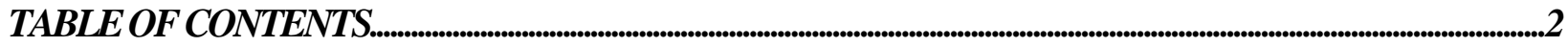

INTRODUCTION

Programmatic Background.

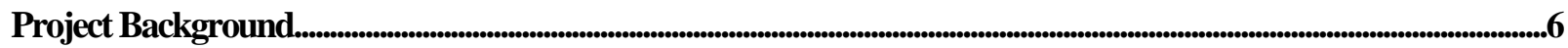

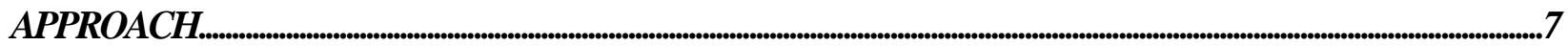

OBJECTIVES.

1. Define IAQ Indicators and Contaminant Sources of Concern......................................................................9

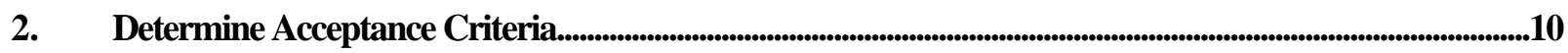

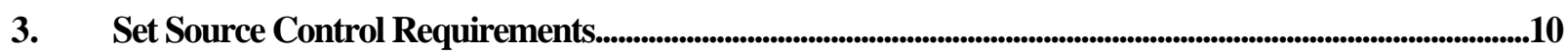

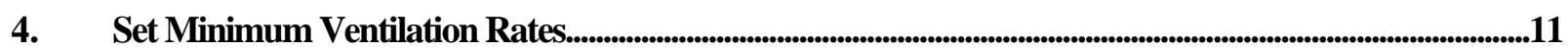

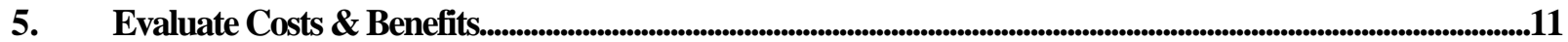

6. Technology Transfer and Research Implementation.....................................................................................................12

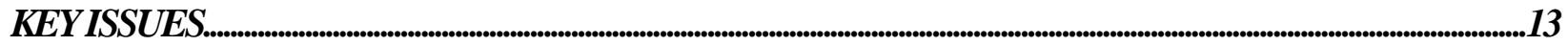

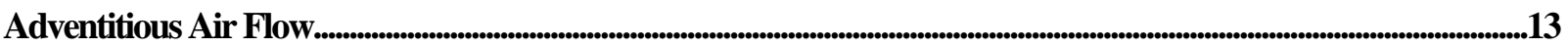

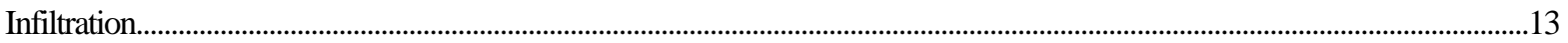

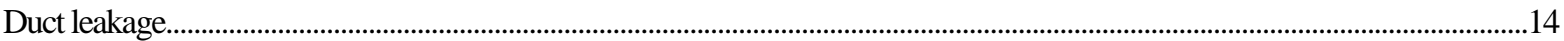

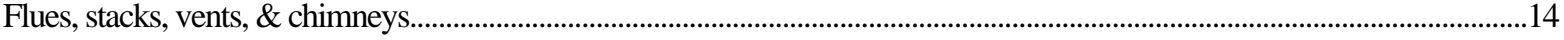

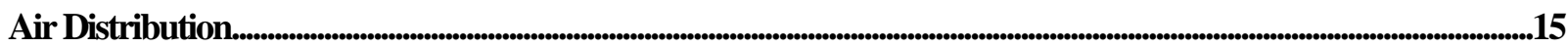

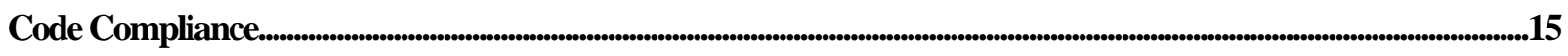

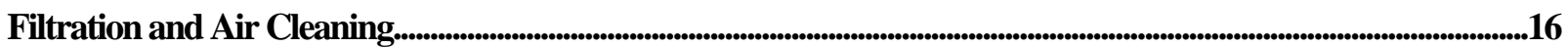

Particle filtration and HVAC Systems.........................................................................................................................................16

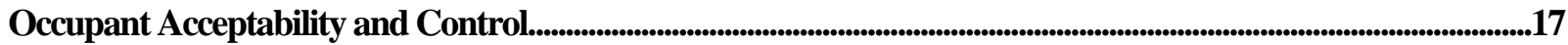

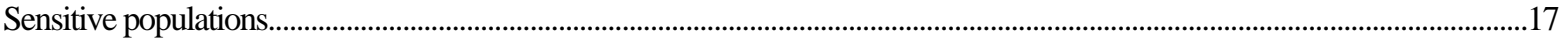

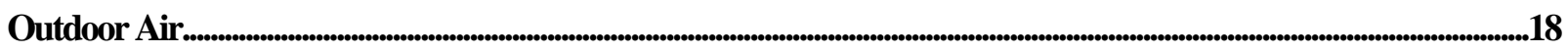

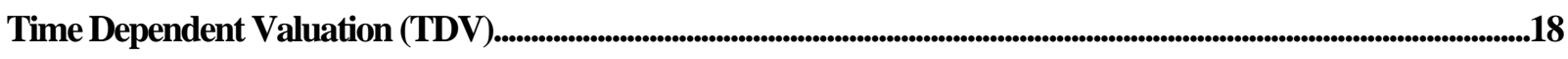

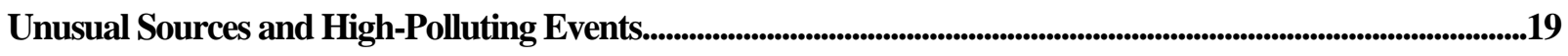

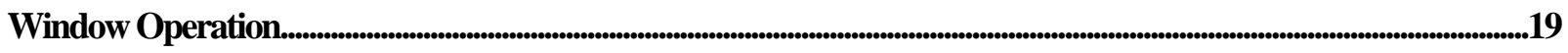

RESEARCH PLAN

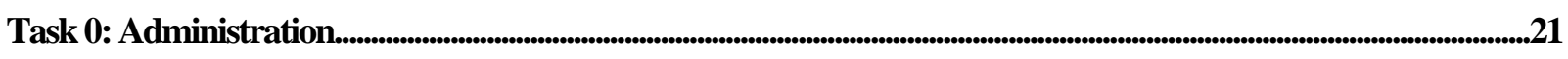

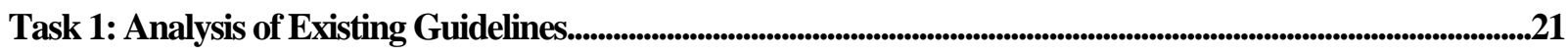

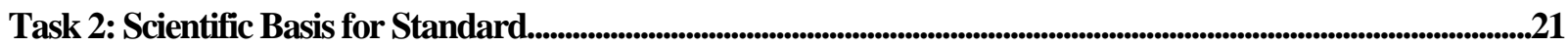

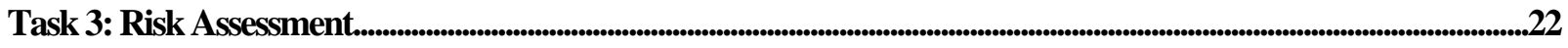

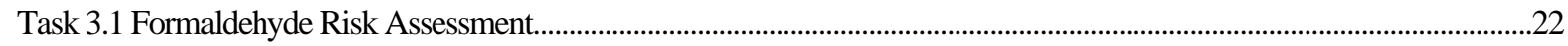


Task 3.2 Comprehensive Risk Assessment..........................................................................................................................2

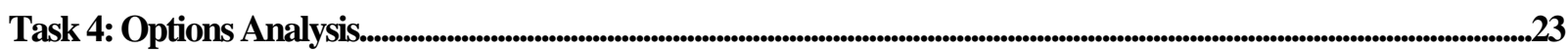

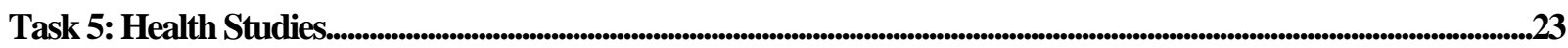

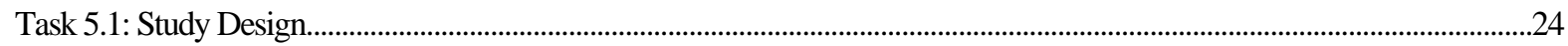

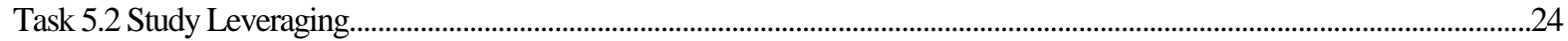

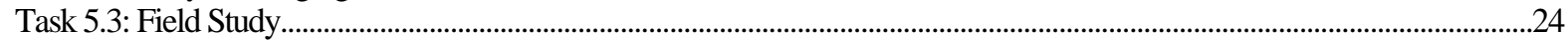

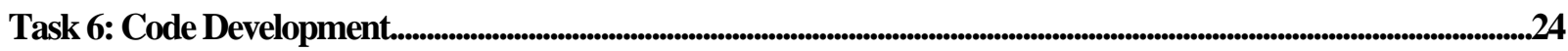

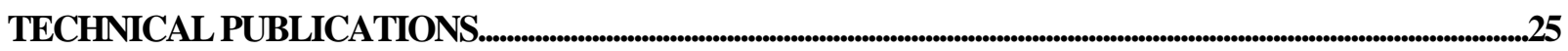

LINKAGE BETWEEN PROJECT GOALS AND RESEARCH PLAN............................................................25

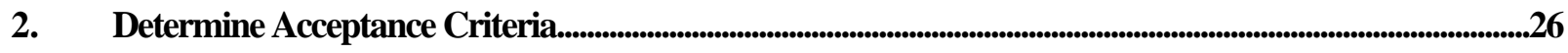

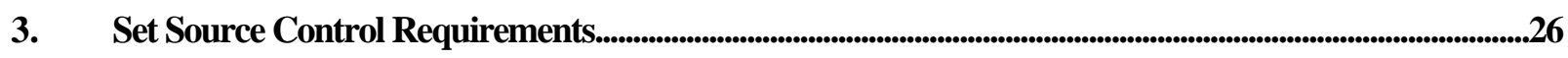

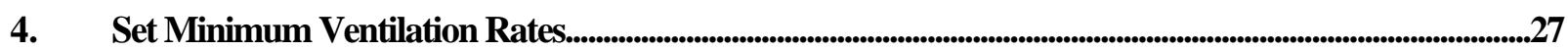

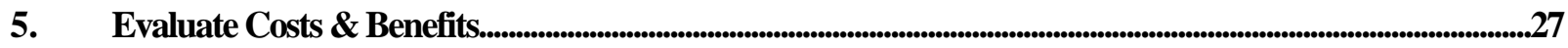

6. Technology Transfer and Research Implementation.....................................................................................................27

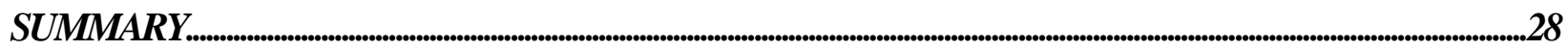

APPENDIX I: VENTILATION, IAQAND HEALTH..................................................................................................29

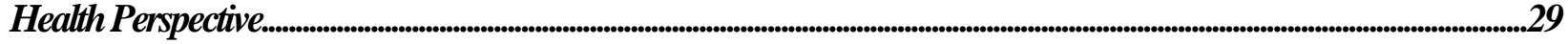

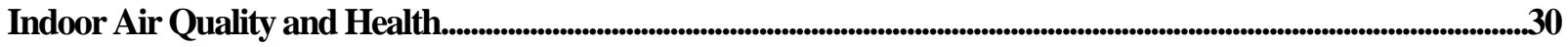

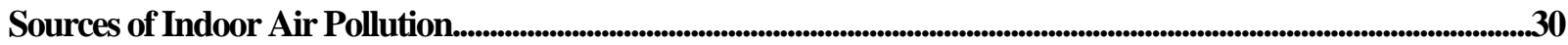

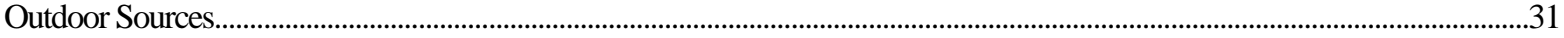

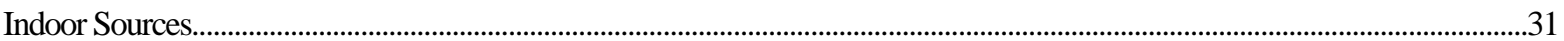

TYPE 1: Hazard Assessment.

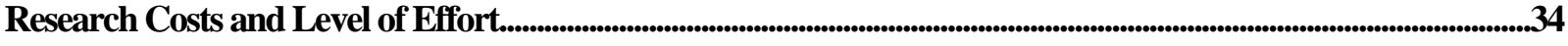

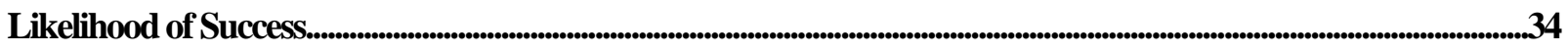

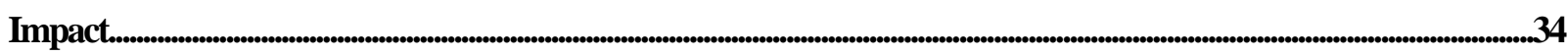

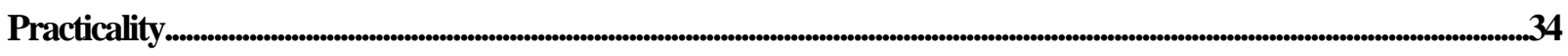

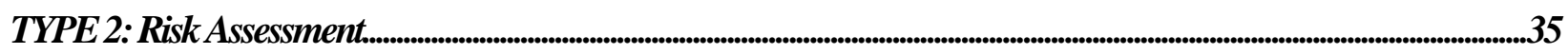

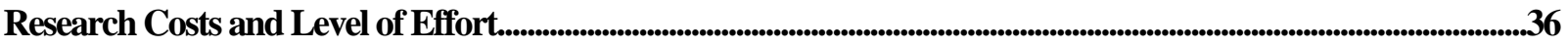

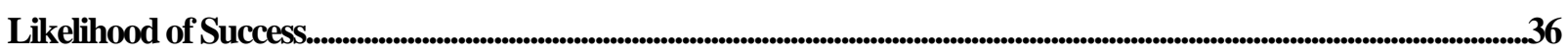

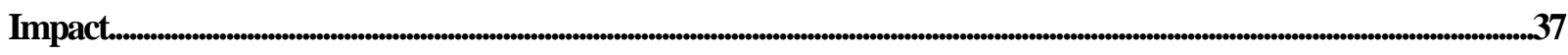

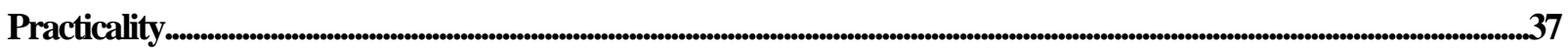

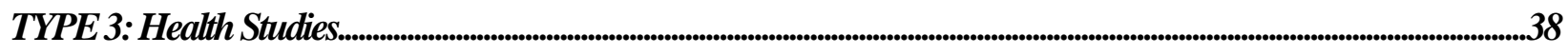

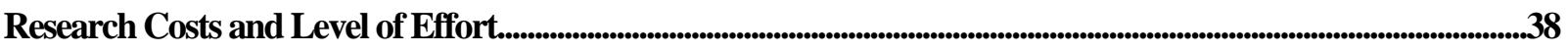

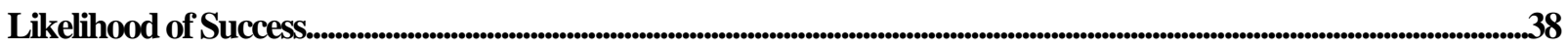

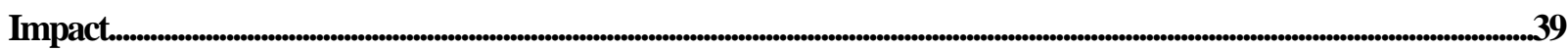

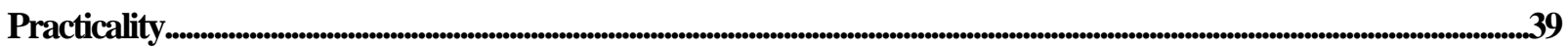

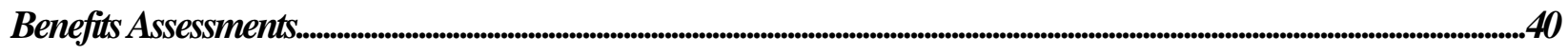




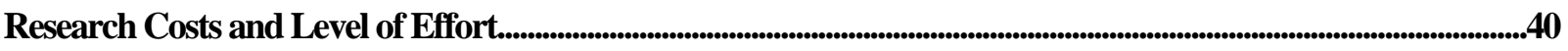

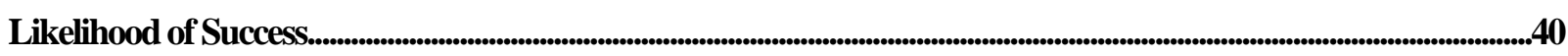

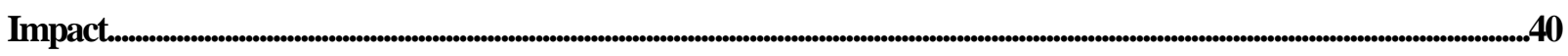

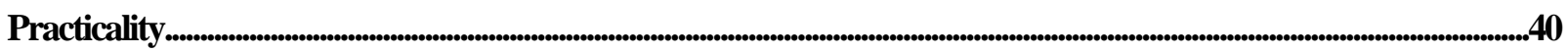

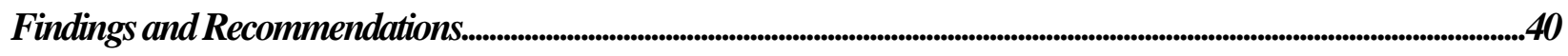

APPENDIX II: List of Energy Codes by State.................................................................................................................................42

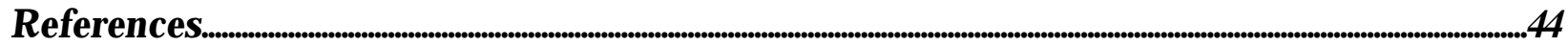




\title{
Residential Ventilation Standards Scoping Study
}

\author{
T. E. McKone and M. H. Sherman
}

\section{INTRODUCTION}

The goals of this scoping study are to identify research needed to develop improved ventilation standards for California's Title 24 Building Energy Efficiency Standards. The 2008 Title 24 Standards are the primary target for the outcome of this research, but this scoping study is not limited to that timeframe. We prepared this scoping study to provide the California Energy Commission with broad and flexible options for developing a research plan to advance the standards.

\section{Programmatic Background}

The California Energy Commission (CEC) has as a funding priority a program of Research and Development (R\&D) to advance the state of knowledge on residential ventilation in California. CEC will support this research through its Public Interest Energy Research (PIER) program. An important goal of this effort is to identify changes to existing residential energy efficiency standards (i.e., Title 24) that can be incorporated into the 2008 standards to maintain or to improve the indoor environment of new homes and to reduce the energy-related impacts of these homes.

To advance the state of knowledge in this field, the PIER program has established a threepart approach to the problem: 1) characterization of the indoor environments of homes built to current standards, 2) development of minimum requirements to achieve acceptable indoor air quality in future construction and 3) evaluation and development of technologies and associated descriptive algorithms for meeting minimum requirements.

These three elements act synergistically to provide the information the State needs to inform its efforts to modify Title 24. Each piece is the subject of an independent scoping study. Together these three scoping studies provide an integrated program of research activities. In order to provide information that can be used for the 2008 CEC Title 24 Standards revision, the goals and required timeline for these projects must be articulated by summer 2005 . This report provides the scoping study for part 2 , the requirements needed to set revised ventilation standards. In order to put this study in context, we describe the three scoping studies and the ways in which they interact are summarized in the following paragraphs.

Characterization Project Goals: The broad goals of the characterization project are: 1) to determine if ventilation and indoor air quality, in a population of new, production-built, singlefamily, detached houses built to 2001 Title 24 energy efficiency standards, are acceptable based on available guidelines for comfort and health protection and 2) to describe the influence of selected key factors, including occupant behaviors, on ventilation rates and indoor air quality in these houses. The objective of this project is to answer a series of questions related to ventilation rates and indoor air quality (IAQ) in production-built, new, single-family, 
detached California homes permitted under the 2001 Title 24 standards. These questions focus on the topics of ventilation, indoor air quality and occupant behavior.

Requirements Project Goals: The broad goals of the requirements project are to: 1) determine the state of the art in residential ventilation codes and guidelines and their applicability to California; 2) identify and resolve engineering-based issues necessary to define new minimum requirements; 3 ) determine how to extend engineering-based requirements with R\&D to incorporate health protection; and 4) develop draft requirements suitable for inclusion in the 2008 version of Title 24. The objectives of the project are to focus on the technical barriers to improved residential ventilation standards and to resolve these barriers. We will closely coordinate work on this project with the characterization project to identify real-world issues and problems for ventilation and indoor air quality in new construction.

Technology Project Goals: The broad goals of the technology project are to: 1) determine the state of the art in residential ventilation methods and technologies and their application to California: 2) identify and develop suitable technologies that meet new minimum requirements and are not currently used in California; 3 ) develop models to evaluate the full performance of potential technology using the applicable criteria of energy, ventilation, demand, etc. and 4) work with the compliance industry to incorporate necessary algorithms into future Title 24 compliance tools.

Throughout this document, when talking about overlaps and synergies, we refer respectively to the three projects above as the characterization, requirements and technology projects.

\section{Project Background}

Title 24 standards for building ventilation are primarily engineering-based and, as a result, technical feasibility is likely to remain a key driver for these standards. In contrast to other residential environmental media, such as tap water, indoor air has not been the subject of explicit health-based standards. An important consideration for all future ventilation standards is the feasibility of making human health protection an explicit goal rather than relying only on a simple engineering consensus approach. The purpose of ventilation is to provide acceptable indoor air quality, to enhance durability of systems and materials and to reduce direct health impacts. In order to support the Title 24 process, the CEC has expressed interest in whether and how ventilation-related requirements could be based on a risk assessment or other health studies. In particular there is an interest in how ventilation requirements could influence contaminant concentrations, and how the resulting changes in contaminant concentrations could in turn have positive or adverse effects on health. This requires an effort to consider existing and new information about the relationships of ventilation rates to contaminant concentrations and to human-health outcomes. This scoping study provides an estimate of the magnitude and scope of the $R \& D$ that would be required to provide an adequate basis to include health considerations in building energy standards. It also provides an assessment of the costs and risks associated with including health considerations.

The current literature provides clear indications of links between human health and ventilation and of the need for addressing these links through guidelines and standards. In research from office buildings as reviewed by Seppanen et al. $(1999,2002)$ relatively strong and consistent associations have been found between ventilation and health. In their review of 105 papers dealing with ventilation and health in non-industrial indoor environments, Wargocki et al. (2002) report that ventilation requirements in many existing guidelines and standards may be too low to protect occupants of offices, schools, and homes from health problems and may not be optimal for human productivity. Wargocki et al. (2002) observe that, although higher ventilation rates can increase energy costs in relation to building operation, these can be reduced by 
several measures such as prudent and systematic maintenance of heating/ventilation/airconditioning (HVAC) systems and by reducing superfluous pollution sources indoors.

A key issue for this scoping study is the effect that alternative ventilation standards will have on energy use calculation algorithms and compliance tools already in use by the California building industry. Addressing this issue requires interaction with the members of the HVAC engineering community who provide compliance tools for the Title 24 Standard. To address this issue requires that any future advisory committees that are convened as part of this project should specifically include representatives from compliance-tool providers.

Another issue to be addressed is the potential for standards to explicitly include peak load energy demand as well as cumulative energy use. In preparing this scoping study we consider how standards would be changed to account for peak load ventilation requirements. In doing this we include potential credits and/or compliance paths for systems that allow load shifting or specifically target energy reduction at peak load conditions in other ways.

In order to address the relationship of ventilation to health for the scoping study, we assess both engineering issues and the feasibility of including health effects in developing standards. We begin with an evaluation of the current Title 24 ventilation requirements and compare them to other state-of-the-art standards, with a particular emphasis on ASHRAE Standard 62.2. We assembled and reviewed other ventilation and ventilation related standards for potential contributions to a California specific standard. In order to establish a portfolio of existing approaches that could have potential use in California, we reviewed the work of organizations such as Building America and European states from the International Energy Agency (IEA). This review has established issues that need further R\&D effort in order to determine components that can be incorporated into future California standards.

For assessing the feasibility of estimating the health impacts of alternate ventilation standards, there is a need to identify the range of health issues to be addressed and then summarize the links between air quality and health that need to be addressed by the standards. We examine here the steps required to make a future ventilation standard include some health-based specifications.

For engineering feasibility, we identify the engineering issues related to providing adequate ventilation without large energy penalties and describe strategies to confront these issues. For this process, we consider five issues: 1) the reliability of occupant control, especially with regard to window opening; 2) distribution of outdoor [or ventilation] air, 3) the role of unusual sources and/or source control, 4) the role of air cleaning and/or particle filtration, and 5) impacts of poor outdoor air quality. We did not cover the performance of specific residential ventilation technologies in this scoping study, but did consider generic criteria for ventilation.

\section{APPROACH}

Title 24 focuses on cost-effective ways to minimize the energy-related impacts of providing building services such as thermal conditioning, lighting, etc. Ventilation is an energy-consuming activity and considered an end use. Ventilation is not, however, considered directly as a building service, rather it is the acceptable indoor air quality provided by ventilation that is a building service.

The current version of Title 24 has ventilation requirements that go beyond the model codes. Other states including Florida, Minnesota and Washington have also adopted ventilation requirements that go beyond model codes. Several European countries including France, 
Sweden, the United Kingdom and Denmark have very specific ventilation requirements. In order to evaluate changes to Title 24, it is important to consider what other codes have specified, as well as what are considered best professional practice (e.g., ASHRAE Standard 62.2).

Ventilation is an energy consuming activity that provides acceptable indoor air quality. There is no fixed "right" amount of ventilation in the same sense that there is no fixed "right" size of furnace or air conditioner. To find the minimum requirements for thermal conditioning, one must determine the thermal load and the desired thermal conditions to be met. Similarly, to determine how much ventilation is necessary, one must look at the sources of concern to indoor air quality (i.e., moisture levels and pollutant loads) and the desired level of indoor air quality. Based on these two factors, the choice of a ventilation level must be made by trading off various costs (e.g., energy costs, first cost, risks, etc.) with the benefits associated with the building service (e.g., health and comfort).

The problems of determining appropriate minima for ventilation are much more complex than those confronted in efforts such as determining thermal insulation levels. Thermal loads are well studied and can be robustly estimated from internal gains and weather conditions. In contrast, pollutant sources tend to be highly variable among different households and are quite dynamic. Thermal comfort can be predicted quite reliably from just a few environmental parameters (e.g., temperature, air speed, humidity, etc.) whereas acceptable indoor air quality depends on a number of environmental and exposure parameters, many without established value ranges or acceptability criteria.

Because of the complexities of IAQ, ventilation standards and guidelines have followed a much more subjective route than thermal standards and guidelines. Extant ventilation requirements are based on evaluations of what has or has not worked and thus incorporate the experience of experts in the field. To be successful this project must respect this philosophy and add additional perspectives to the work that has gone before instead attempting to move to quickly in an alternate direction.

In the long term, ventilation standards will likely be based on a better understanding of contaminants in the indoor environment and their effects on health. While the current state-ofthe-art in IAQ research is not sufficient to provide a truly health-based ventilation standard, current IAQ research is sufficient to improve upon the more traditional engineering-based approaches by including some measure of health protection. By incorporating measures of health protection, ventilation standards can be used to simultaneously reduce ventilationrelated costs and improve the indoor environment, with a resulting improvement in Californians' overall quality of life.

Using health-related assessments to determine acceptable air quality is not a novel approach for regulatory bodies such as the US Environmental Protection Agency (USEPA), the California Environmental Protection Agency (Cal-EPA) or for the broader public-health community. It is, however, novel in the context of California building standards. To assist the CEC in evaluating R\&D options, we provide in Appendix I an expanded explanation of how these kinds of assessment can be used in the context of building standards. Appendix I describes four different kinds of assessments that can be used in the development of residential ventilation requirements: hazard assessments, risk assessments, health studies, and benefit assessments. Also in Appendix I, we discuss the uses, costs and uncertainties of each approach. We compiled these latter findings in order to support our scoping effort and limit the risk of project failure. As is discussed in Appendix I, there are clear opportunities and benefits for using health protection as an explicit basis for setting ventilation standards but there are also clear limitations and risks. Among these limitations are large uncertainties in the links between exposure and disease at low dose rates, the lack of consensus about setting 
acceptable levels of exposure, and the need for making trade-offs among health benefits and cost, feasibility, energy use in applying ventilation standards.

In Appendix II we provide for reference a list of energy codes used by various states along with the structures covered by the codes and the bases for the codes, whether a health or other basis.

\section{OBJ ECTIVES}

We identified five objectives necessary to achieve the goals of this project. These are 1) define health and exposure indicators and contaminant sources of concern; 2) determine acceptable indoor contaminant exposures, exposure indicators, and indoor concentrations; 3 ) set source control requirements; 4) set minimum ventilation rates, and 5) evaluate costs and benefits. As noted above, these objectives are interactive and cannot be easily achieved in isolation. The process for achieving these objectives is discussed in the following paragraphs.

\section{Define IAQ Indicators and Contaminant Sources of Concern}

Indicators of IAQ include observed chemical concentrations as well as factors that indicate the potential for exposure, such as certain types of building materials, moisture, visible mold, gas stoves, wood burning stoves, etc. There is a large number of substances that might be found in the indoor air. Many of these can cause health or safety problems. But it is likely that only a relatively small list of pollutants actually pose health concerns at levels encountered in residential environments. Thus, we directed the component tasks of this objective so as to assemble a short list of substances and source indicators of concern. As outlined below, this information can be gathered in several different ways.

- Historical: People have been ventilating buildings for a long time and the scientific and engineering literature contains records of how and why they ventilated. Historical reasons for ventilation include controlling the products of combustion in addition to human bioeffluents and contagious agents.

- Imputed: Existing recommendations, standards and guidelines may not be based on first principle analyses of pollutants, but one can infer from the requirements useful information about what these recommendations, standards and guidelines are designed to control.

- Observational and Published: A review of the published literature can determine what key contaminants or indicators of exposure ${ }^{2}$ have been found in relevant indoor environments. Similarly the companion characterization project will generate data on what is most frequently found in California residences.

- Authoritative: Regulatory bodies and other cognizant authorities keep lists of contaminants they believe to be of significant concern. These lists should be reviewed to determine what contaminants are most appropriate for California.

The hazard-assessment approach referred to in Appendix I is of particular value in determining the contaminants of concern.

\footnotetext{
${ }^{2}$ Exposure indicators often serve the same function as contaminant concentrations, but may not themselves be contaminants of concerns. For example, water vapor is not a contaminant of concern, but can be an indicator of moisture related problems. Similarly carbon dioxide is not a contaminant of concerns at concentrations found indoors, but can be a surrogate for human bioeffluents.
} 
The list of contaminants of concern may be further limited by excluding those that are determined not to be within the scope of Title 24. For example, protection of one occupant from the carcinogenic effects of Environmental Tobacco Smoke (ETS) from other occupants is not within this scope. The determination of which contaminants are appropriate for considering is a Key Issue and must be addressed.

\section{Determine Acceptance Criteria}

For each contaminant of concern it is necessary to have a measure of what constitutes successful control. That is, what are the contaminant-specific acceptance criteria of indoor exposures, exposure indicators, and indoor concentrations? In principle, such acceptance criteria can be quite complex, as they can involve many interacting contaminants and susceptibility factors.

The most thorough way to set acceptance criteria is to initiate a significant health research effort along the lines of what is described in Appendix I under the topic of health studies. Because epidemiological health studies include an explicit link between ventilation and observed health status, exposure acceptance criteria based on these health studies would be comprehensive and highly credible. But the magnitude and timescale of this effort is beyond what the CEC can afford to achieve within their overall goals for Title 24. Because of the cost and complexity of comprehensive health studies, we recommend that such studies should not be considered as the primary basis for determining acceptance criteria. If another organization such as USEPA, the California Air Resources Board (CARB), National Institutes of Health $(\mathrm{NIH})$, Department of Housing and Urban Development (HUD), etc., is undertaking such an effort, it is recommended that CEC consider augmenting the effort to see that sufficient California-appropriate information is gathered to facilitate future improvements.

For the purposes of this project the acceptance criteria should be developed as simple concentration targets (formaldehyde concentrations, nitrogen dioxide levels, particle concentrations, etc.) or exposure indicator targets (moisture levels, observable mold, etc.) based on the need to minimize health outcomes. Health outcomes include chronic disease such as asthma, allergies, cancer, neurological development, and chronic headaches, coughs, and colds. The link between exposure and health outcomes can be obtained from an appropriate combination of hazard assessment, risk assessment, health studies, and/or benefits studies as defined in Appendix I. In some cases these concentration targets can be based on existing pollutant standards and in other cases they will be based on inference and engineering judgment.

\section{Set Source Control Requirements}

Source control is generally recognized as the first and best approach to controlling contaminants. Typically, the use of source control to keep a pollutant out of the indoor environment is easier and less expensive to implement, and more energy efficient than the use of whole-house ventilation to dilute the pollutant. Many existing standards and guidelines have explicit and implicit source-control requirements. There are two kinds of source control measures that must be evaluated: process and material.

Process source control is used when an activity generates the contaminant. For many normal household activities process control is familiar and include such things as ventilation of combustion equipment (and dryers), or exhaust fans in kitchens and bathrooms. Occupant controlled windows can sometimes be treated as process source control and typically are when the activity generates odorous contaminants such as at large gatherings, when painting or cleaning, or for some hobby activities. Process control can also be employed during 
construction. How a contractor stores material, protects ducts, etc., can have a big influence on future sources.

While process source control is normally integral to the building system, material source control often requires restrictions on the use of some product. Many building materials, for example, emit Volatile Organic Compounds (VOCs), which can negatively impact IAQ. Material source control involves either reducing unwanted emissions from identified materials or limiting their use.

Based on the contaminants of concern and their acceptance targets, a set of source control measures must be developed. The more effective the source control measures are, the less will be the need for dilution through ventilation.

\section{Set Minimum Ventilation Rates}

Setting the actual dilution (that is, whole-building) ventilation rate that is needed to meet acceptance targets is the last step of the requirement development process. The wholehouse ventilation rate should be set in order to dilute the contaminants that cannot be further controlled by source control and to provide some margin of error for the contaminants that were not identified and to address uncertainties in source strength and population susceptibility.

Filtration and air cleaning should be investigated as options to achieve lower minimum ventilation rates. When the minimum ventilation rate is dominated by a single pollutant class, filtration and air cleaning have the potential to reduce energy impacts by allowing lower wholebuilding ventilation.

Many existing standards and guidelines have based the selection of acceptable ventilation rates on factors that are not well understood. As a result these standards and guidelines must address uncertainties by including an adequate margin of safety in any recommended values. In order to establish a starting point for assessing links between ventilation and health, we use a reasonable "margin of safely" approach as a starting point. This approach will provide continuity with existing guidance.

The risk assessment process as described in Appendix I provides a valuable opportunity for CEC to use well-established tools and datasets developed by other agencies to set more defensible residential ventilation standards for California. The use of risk assessment in combination with established procedures based on engineering judgment for ventilation standards increases both consistency and defensibility of the standards. Although this scenario makes the R\&D effort worthwhile, we recommend that health-based assessments be employed in step-wise and clearly defined stages. These stages include hazard assessment, risk assessments of increasing sophistication, and health studies. These stages are discussed in more detail in Appendix I. By approaching the process in stages and avoiding an initial commitment to a full-blown risk assessment, the CEC can determine what level of health assessment supports the key goals of this project. The staged risk assessment makes it possible to assure that any health assessment is informative without becoming a burden to the engineering aspects of defining ventilation goals.

\section{Evaluate Costs \& Benefits}

Ventilation standards do not lend themselves to traditional benefit/cost analyses because of the difficulty in assigning a dollar value to the benefit side of the equation (particularly for health benefits) and because of the large spread of reasonable costs. 
Nevertheless it is important to evaluate both the costs and the benefits of alternative ventilation requirements. Appendix I describes the types of benefit assessments that might be considered. An important aspect of such benefit assessments is that they can allow trade-offs in achieving a number of competing objectives. Benefit assessments also address the issue of setting an acceptable level of risk in the context of competing risks and costs.

The technology project referred to and summarized in the introduction will have a strong focus on minimizing the cost and maximizing the energy savings of whatever requirements are developed in this project. But the ventilation requirements project under consideration here must also provide at least qualitative cost evaluation to assure that any requirements proposed are reasonably achievable.

Another aspect of evaluating costs and benefits of any proposed standards is how the requirements imposed and the equipment necessary to meet these requirements address (or are impacted by) the Key Issues described below. Research has demonstrated that a whole host of practical and behavioral issues can impact the success or failure of residential standards. Our analysis of key issues is likely to reveal that some additional requirements are necessary in order to assure proper delivery of the intended service. (An example of such a requirement would be a certified rating on a fan.)

The standards evaluation process must be an on-going process because it is quite likely that such an analysis will come up with trade-offs that could improve the standard. An example of such a trade-off might be lowering whole-house ventilation rates when only low-emitting building materials were used, or increasing them in the presence of certain kinds of combustion processes.

\section{Technology Transfer and Research Implementation}

More than an academic exercise, this study and its results will be used to improve the quality of life and standard of living of Californians. It is, therefore, important that the results of the study are usable for and used by decision-makers in the State.

The primary implementation mechanism of this study is focused on the incorporation of the results of this study into Title 24 . Thus the results of the study must be compatible with the needs and mechanisms of the State in managing its regulatory process. The timing of the study must accordingly match that of the public process that is integral to modifications of regulations. Similarly, the level of rigor, complexity and stringency of any recommendations must be appropriate for a "codes" process.

While Title 24 may be the primary focus of the connection to the market, other mechanisms need to be considered and included. All scientific results need to be published in appropriate literature to assure the quality of the research and to provide an archive of the work to allow, inform, and support future development.

Direct technology transfer activities such as working with builders, code officials, utilities, etc., not only helps get the information out to interested parties quickly, but also allows feedback to the researchers from those who are most directly impacted by potential changes. Thus it is important to have an on-going involvement with potential implementers during the research. 


\section{KEY ISSUES}

In scoping the R\&D necessary to develop new requirements for residential ventilation in California, we have identified several key issues that require further consideration. The goals and objectives of this project cannot be adequately achieved unless these key issues are addressed and resolved in the course of the project.

\section{Adventitious Air Flow}

Objective 4 above will require that we determine how much whole-house ventilation is necessary to meet health and comfort. But this effort will not tell us where that ventilation comes from. Ventilation can come from mechanical systems or envelope airflow either intentionally or unintentionally. Adventitious Air Flow refers to all forms of unintentional or incidental airflow that can contribute to the total ventilation.

In order to size any designed ventilation system, it is important to know the amount of adventitious airflow that would occur without a designed system. In principle some of this can be measured, but in practice a ventilation requirement usually makes some reasonable assumption about the relative magnitude of this ventilation.

\section{Infiltration}

Infiltration is weather-induced airflow through leaks and cracks in the building envelope. The building stock in the United States has traditionally been relatively leaky such that building scientists estimate that the average home has over one air change per hour due to infiltration. This high value satisfies the ventilation requirements of virtually all ventilation standards and guidelines, so most existing homes may not need any additional ventilation system.

New construction on the other hand is quite different. New construction in the U.S. is a factor of 3-4 tighter than the existing stock. At this tightness level many houses are unlikely to receive sufficient ventilation from infiltration. To save energy, however, it is important to determine how much "credit" to give for infiltration. This calculation can avoid over sizing the designed ventilation system for overall dilution.

While measured data have been collected and analyzed for the for existing housing stock and new construction in the US as a whole, there has been no such study for California construction in several years. Data from the complimentary characterization project will help in this regard. Additional analyses of existing datasets should provide a good estimate of what is happening in current California construction.

The amount of ventilation measurement data available will likely always be limited due to the expense of collecting it. Furthermore, datasets of convenience often have hidden biases because they are collected for purposes other than random infiltration sampling. Another way of estimating infiltration credit is to examine default values that may be included in codes and standards.

Currently, California Title 24 provides several air tightness values using the metric of Specific Leakage. Among these values there are distinct value ranges. There is a high default value range that is used in a general manner to minimize set for energy use; a value range that represents an unusually tight structure where special care must be taken during construction; 
and a range of values that depending on whether or not there is an air barrier installed. These values were thought to be appropriate in 1998.

ASHRAE Standard 62.2 has a default infiltration value expressed in terms of airflow per square foot. Although this number is expressed in terms different from Title 24, it is generally more conservative than what is specified in Title 24. Both documents allow a measured value to be used when it is available in place of default values. This approach is an important feature that should be preserved in any new code.

Most current codes and standards do not provide explicit infiltration defaults. Some standards focus on mechanical ventilation systems and how they should be sized. The bodies that created these standards may have assumed some implicit values for infiltration, but, based on what is provided in the standards, it is not clear what value was assumed. During the course of this research there is a need for a more in-depth analysis of standards documents in order to determine what infiltration values are assumed in current standards.

We recommend that these various codes and standards be compared to identify an appropriate set of default infiltration assumptions for any new set of requirements. Use of modeling tools such as the LBNL infiltration model or ASHRAE Handbook of Fundaments must be used to incorporate infiltration with designed ventilation systems.

\section{Duct leakage}

Research has demonstrated that duct leakage in California can easily triple the natural infiltration rate. In fact it is quite likely that in the new houses built in the 90 s, duct leakage was the dominant source of ventilation because of leaky ducts and relatively tight building envelopes.

While duct leakage can in principle provide an important source of ventilation, it is highly energy inefficient and it is always better from a cost standpoint to reduce it. For these reasons, no ventilation code or standard we could find allows credit for airflows induced by duct leakage.

It is important to recognize that duct leakage in return ducts could serve to reduce indoor air quality. When return ducts or air handlers are in attics, crawlspaces or garages, they can be a source of contaminants rather than providing effective dilution ventilation. These types of buffer zones can often have chemical or biological contaminants that should not be transferred into areas occupied by residents. As part of the R\&D project, the role of duct leakage as a pollutant source must be investigated to determine if source control requirements are necessary.

Flues, stacks, vents, \& chimneys

There are a variety of intentional penetrations in a typical home that are used to exhaust contaminants of one form or another. When these components are in operation, they provide desirable source control measures, but when they are not in operation they can provide an unintended source of extra ventilation. Combustion appliances and local ventilation systems are the most common reasons for such penetrations.

This extra ventilation is not normally accounted for in the existing codes and standards. At best this type of ventilation is implicitly lumped into the infiltration number. Because most of these penetrations are relatively large openings and in vertical shafts, they behave differently 
than simple leakage. There are currently available modeling tools that can examine the ventilation and energy impact of these penetrations.

This R\&D project needs to provide the necessary information for ventilation requirements to adequately reflect the ventilation contribution of these penetrations. This information will assure that the Technology project can develop appropriate algorithms to find the optimal system.

It must also be noted that many of the penetrations that provide inadvertent ventilation can also become pollutant sources by processes such as back drafting, if the system is not configured properly. This effect must be considered as part of source control evaluation.

\section{Air Distribution}

Almost all ventilation standards and guidelines have provisions for local ventilation to remove contaminants from rooms known to have specific sources. In homes, kitchen and bath fans are often required for source control. However, many standards like those in ASHRAE or Title 24 assume that contaminants and ventilation air are evenly distributed throughout the home. As a result, they treat the house as a single zone and thus only set single-zone ventilation requirements. To the extent that there is an air distribution system that keeps the air mixed, this is appropriate.

On the other hand, some standards, such as those in Europe, typically require minimum ventilation rates for each habitable room. This divergence is undoubtedly due to the difference in the housing stock and air distribution systems between the two cultures. California has typically had leaky houses with forced air distribution systems, while Europeans have tended towards tighter houses with hydronic distribution systems.

As space energy demands in houses continue to decrease due to improved thermal envelopes, the circulation of ventilation air in a forced-air system will also decrease. Losses in air distribution systems can be significantly reduced by the use of hydronic systems. It is possible that the use of these systems will increase over the next few years.

We believe that an essential part of the $R \& D$ of this project is to examine what constitutes a minimally-acceptable air distribution system. This information will assure that indoor air quality will not be compromised as trends toward alternate heating (and cooling) systems develop.

\section{Code Compliance}

The ultimate goal of this project is to support CEC efforts to develop a residential ventilation code that is practical, adoptable, cost-effective and protective of occupant health and safety. To do so requires that the results of this effort meet not only the technical objectives outlined above, but are also compatible with the requirements of many of the stakeholders in the area.

To assure that this process begins as soon as possible, we recommend that a project advisory committee be formed with stakeholders selected by the CEC. The task of this committee is to monitor the research process and provide feedback on both the health and engineering issues.

There are two phases to the code-development component of this project. The first phase will develop language for potential adoption into Title 24 . This phase must be covered by the tasks described in this scoping study. The second phase is to develop algorithms suitable for incorporation into Title 24 compliance tools. Because this phase requires a much more 
detailed understanding of the particular technologies involved, it is recommended that this phase be carried jointly with the Technologies project. A special joint advisory sub-committee could be formed to coordinate work among researchers on the two projects with regard to this second phase of the code development.

\section{Filtration and Air Cleaning}

Whole-house ventilation reduces exposures to dispersed indoor contaminants by diluting them with outdoor air. Another method to reduce exposure is to extract contaminants from the air with filtration or air cleaning. Doing so can, in principle, reduce the requirements for dilution ventilation and thereby save energy and operating costs.

Since such strategies are pollutant specific, it is important to understand the contaminants of concern before attempting to remove them. Furthermore, for such strategies to succeed often requires more care and/or maintenance and the cost of these actions must be included in trade-off assessments.

An air cleaning or filtration system can be developed for almost any pollutant of concern. But in terms of what is most practical, the current literature lists particulate matter and ozone as pollutants for which filtration is readily available. When airborne organic compounds are an issue, air cleaning can become quite expensive and more cost effective alternatives must be considered.

As contaminants of concern are identified in this project, the project researchers must investigate the practicality of filtration and air cleaning. It may be possible to develop trade-off mechanisms between air cleaning, source control and dilution ventilation. The practical aspects of installation and operation must also be given due consideration.

\section{Particle filtration and HVAC Systems}

In the section above, we discuss filtration and air cleaning as alternatives to dilution ventilation for known sources. No current residential ventilation standard has such a mechanism at minimum rates, although some may allow it for special purposes. In contrast, ASHRAE 62.2 (among others) does specify filtration as a mechanism for keeping the HVAC system from becoming a source.

When dust and dirt build up on components of HVAC systems, those components can become contaminant sources. In climates that require cooling, water collected in the HVAC system can combine with organic materials in the dust and dirt, allowing mold to grow in and then be disseminated by the HVAC system.

This so-called "wet coil" problem has been more severe in humid climates than in California. As sensible loads are reduced through better building envelopes, however, latent loads will represent a large fraction and wet-coil operation will be more common.

Another source of contaminants from HVAC particulates comes from semi-volatile organic compounds (SVOCs) that are produced in the residence but condense and re-volatilize in the HVAC systems. These are compounds that are do not partition to a significant extent into the gas phase at room temperatures, but have a sufficiently high vapor pressure to volatilize to some extent into room air. Incomplete combustion processes (e.g., fireplaces, cooking, "candle soot", etc.) can be important sources of SVOCs, which exist as particles or stick to particles and evaporate slowly over a long time. Furthermore, because they tend to increase their re-emission rates when their corresponding air concentration is lowered, many SVOCs are 
resistant to dilution ventilation. An optimum mechanism for dealing with these types of contaminants is to filter them out of the air (and then remove the dirty filter).

An added factor, which is important for energy consumption but not for IAQ, is that particles can build up and greatly reduce the efficiency of evaporator coils. This effect will have the impact of reducing the system efficiency and capacity over time. Reasonable filtration has been shown to double the life of indoor coils.

ASHRAE 62.2 requires a MERV 6 filter (measured using ASHRAE Standard 52.2) to protect HVAC systems. This is a low-to-intermediate filtration level that was not intended to address human health protection. The issue of minimum filtration levels must be reexamined for Title 24 , especially in conjunction with air-distribution requirements in any revised standard.

\section{Occupant Acceptability and Control}

The purpose of residential ventilation is to provide acceptable indoor air quality for the building occupants. Not only must the occupants find the indoor air acceptable, they must find the systems that they have to interact with acceptable. Thus it is important to consider a wide variety of occupant-related issues when developing minimum requirements.

On example of such an issue is noise. Ventilation and air distribution systems can generate noise. Occupants who are bothered by noise may defeat the ventilation system. It is, therefore, important that fans and other components not generate excessive noise. ASHRAE 62.2 sets sound limits for both continuous and intermittent fans. These limits need to be examined and made relevant for California.

Similarly, annoyed occupants are likely to disable ventilation systems that create drafts or other thermal discomfort. Literature from the Pacific Northwest and other climates demonstrate that people would rather have insufficient ventilation than have cold air blow on them. Systems that are inherently uncomfortable should be avoided.

Research demonstrates that occupants feel more comfortable when they have control over their environment It is important that occupants have some level of control of their ventilation systems. They must have the ability to disable it for service or emergencies; they must have the ability to increase ventilation for events such as parties, cleaning, hobby activities, etc. when they know they will need extra dilution.

But because occupants are, in general, not trained to sense IAQ and ventilation needs, ventilation systems must be able to run simply, automatically and unobtrusively. A review of occupant issues with respect to ventilation systems should be done before requirements are made final.

\section{Sensitive populations}

Building standards are typically designed to specify minimum requirements and to address the needs of a majority of occupants. It must be recognized, however, that there are special populations who have greater sensitivities to some contaminants (e.g., allergies, compromised immune systems, airway disease, etc.) and will, therefore, experience discomfort with contaminant levels that elicit no response in most people.

While it may not be appropriate to design new standards to protect the most sensitive populations, it is appropriate to encourage the development of systems that such populations can upgrade to meet their needs and to determine the extra protection from contaminants 
appropriate for such populations. Therefore, it is important that the impact of various choices on sensitive populations, and their needs, be assessed during the development of these requirements.

\section{Outdoor Air}

In designing residential ventilation systems to dilute indoor contaminants, engineers usually assume that the outdoor air itself is of acceptable quality and contains low levels of contaminants of concern. Unfortunately, in many California regions, outdoor air quality can be poor during some parts of the year, thus refuting this assumption.

Some ventilation system designs can provide various forms of protection for short-term outdoor contamination incidents. Ozone, for example, is highly reactive and can be reduced simply by pulling air through the building envelope instead of through large openings such as windows. This is what happens when exhaust fans provide primary ventilation. If filtration is part of the HVAC system, then supply ventilation systems can help remove particles (e.g., pollen, dust, anthrax)

Occupant-controlled ventilation systems and tight envelopes can allow a house to float through a few hours of bad outdoor air, whether it is from burning, pesticide spraying, or accidental or intentional release of toxic substances.

The design of specific residential ventilation technologies to accommodate poor outdoor air is an explicit part of the Technologies project. But incorporating the design flexibility to consider several alternative approaches must be part of the standards development process.

\section{Time Dependent Valuation (TDV)}

The phrase "All energy is equal, but some energy is more equal than others," describes a recent change made to Title 24 to place time-dependent valuation (TDV) on energy use. The philosophy of TDV is to make energy demand more uniform by increasing the value and cost of energy consumed during peak-use periods.

The energy cost of ventilation is not constant because it depends not only on the ventilation rate, but also on the enthalpy difference between indoor and outdoor air. Ventilation energy cost can be quite high during the peak-demand weather conditions (heat of summer and cold of winter). But during mildly warm conditions when ventilation supplies free cooling, its cost is low and can even be negative.

If ventilation rates remain constant throughout the year, little could be done to respond to these cost variations. But health studies indicate that it is possible to reduce pollutant exposures without specifying a constant ventilation rate. For many pollutants it is not the instantaneous concentration that is of significance, but an occupant's cumulative exposure to that pollutant over long time periods. To the extent that we can understand how time-varying concentrations contribute to overall exposure and health risk, we can allow the flexibility in ventilation technology to minimize energy impacts under the TDV scenario. A strategy that has higher ventilation rates when the TDV is low and lower rates when it is high could be designed to provide the same or lower cumulative exposure limits at lower energy impact than a system with a constant ventilation rate.

Although the development of the technologies and their energy impacts is part of the Technologies project, this project must develop requirements that have the flexibility to accommodate optimum use time-dependent ventilation. To do so requires an understanding 
of how the daily profile of contaminant concentrations within a residence impacts the cumulative intake of those contaminants.

\section{Unusual Sources and High-Polluting Events}

As a code, Title 24 specifies a minimum level of ventilation. Users are free to go beyond that level, but may not go below it. In a practical sense this situation requires that research supporting Title 24 identify both those hazards for which the code provides protection and those for which it does not.

From a residential ventilation perspective, one must determine whether the control of a particular contaminant source has been included in the ventilation design. Often this is done implicitly, for example, by using existing requirements as a basis for ventilation requirements. However, it must be made clear what protections are provided regardless of whether protection results from implicitly or explicitly from ventilation requirements.

During the development of ASHRAE 62.2, for example, the working group specifically excluded certain categories of sources from consideration. That does not mean that the standard does not give some protection from those sources, but that the required ventilation rates and other requirements were not designed to do so. In developing requirements for California it will be important to determine which contaminants are excluded.

ASHRAE 62.2 defines a class of sources called "high-polluting events" as "isolated and occupant-controllable events that release pollutants in excess quantities." It goes on to say that acceptable IAQ may not be provided in the presence of high-polluting events even though the standard has been met. It similarly excludes unvented space heaters, but for political rather than technical reasons.

Unvented combustion of all types (cooking, candles, smoking, heating) can be the most problematic of "excluded" sources, but other occupant activities such as refinishing furniture, cleaning, pest removal, office work, etc., must be considered in the course of the research.

\section{Window Operation}

Some organizations, such as the National Association of Home Builders, contend that ventilation standards are not needed because windows can reliably supply any needed wholehouse dilution of indoor contaminants.

It is probably true that windows could supply that ventilation, but there are many reasons why occupants do not choose to open their windows:

- Draft and thermal discomfort

- Noise, outdoor contaminants and insects.

- Security and safety

- $\quad$ Energy costs

- Access and difficulty of operation

Nevertheless, it must be acknowledged that people do tend to open their windows if they perceive an indoor air quality problem. But occupants can readily perceive only a limited 
number of indoor air quality problems. For example, bad odor is often a good indicator of bad $I A Q$, but lack of odor is not an indicator of good IAQ.

Currently both ASHRAE 62.2 and Title 24 allow window operation as an acceptable means to ventilate most California homes. But it must be noted that many in the air-quality research community have questioned this assumption.

The Characterization project will provide some new information on window usage patterns and occupant perspectives on windows. It is also necessary to consider actual effects of window use on ventilation rates. From that work and existing research, this project must determine when it is appropriate to consider window opening as part of a minimum standard and when it is not.

\section{RESEARCH PLAN}

In order to address the key issues identified above and to achieve the corresponding goals and objectives in a timely manner, we must initiate a vigorous program of research relatively quickly. In this section we lay out research plan that addresses the issues, goals, and objectives described above.

This section provides a prototype research plan that does not have the level of detail normally expected in a proposal or contract document. We provide our best estimate of what is needed but we do not consider this a formal proposal or as directly suitable as a contract document. It should serve, however, as a constructive basis for the formulation of whatever contract mechanism the Commission may wish to pursue.

In the process of defining research activities, we have identified various activities as being of high, medium or low priority. We believe all of these projects can help meet the objectives of the State and are worth pursuing. We believe those ranked high are critical to the success of the overall program. Those ranked medium should be done and have the potential to greatly improve the outcome of the project, but we believe the overall project might still be successful without them. Low priority projects are valuable and worth investing in, but are of sufficiently high risk, high cost, or long duration that they should be the first ones considered for elimination if there is a budget constraint.

The budgets for various activities are approximate cost estimates for the minimum amount of effort needed to achieve the research objectives. Except where explicitly noted, the budgets do not include administrative burdens or contract overheads that might be required to convert these activities into a stand-alone program.

Deliverable dates are based on the assumption of start date of December 1, 2003 and should be adjusted depending on actual starting dates and timelines. We assumed that all critical path deliverables would be completed by June 30, 2005 to allow the Commission time to implement them in the 2008 standards. The program of work continues for an additional year to allow time for technical reports to be completed, to provide resources for the researchers to assist the CEC in preparing for hearings or other standards-implementation activities, and to complete any technology transfer activities. 


\section{Task 0: Administration}

The individual tasks described below will achieve the goals and objectives outlined above, but the Commission may wish to have various administrative and coordination tasks accomplished in a manner similar to its programmatic contracts.

The Administration task provides the support needed to coordinate activities, manage the Project Advisory Committee, organize project reviews, prepare quarterly reports, create and maintain a project website, and prepare a project final report. This task also provides a person to interact with the Commission and its contract manager on administrative issues.

Priority: [required]

Quarterly Reports \& website updates: March 2004-March 2006

Interim Project Report:

January 2005

Critical Project Review:

February 2005

Draft Project Final Report:

January 2006

Final Project Report:

May 2006

Approximate Cost:

$\$ 150 \mathrm{~K}$

\section{Task 1: Analysis of Existing Guidelines}

In the scoping study above, we identified a few of the most important residential ventilation codes and standards in order to develop a series of objectives and identify key issues. The purpose of this task is to do an in-depth comparison of a larger set of residential IAQ and ventilation guidelines, standards, and codes to compile a summary of what others have done. In addition to making use of published documents, we will also seek out documents in development to assure that we are able to establish what is the state of the art.

We will provide the result of this task in a report that analyzes each available and emerging document on ventilation standards with respect to the five objectives and all key issues raised in the scoping study. Each document will be evaluated and compared to the others to find areas of agreement and disagreement and to determine the relevance to California conditions.

The results of this task and the report transmitting these results to CEC will serve as resources for the other tasks in the project and also for the Technology project.

$\begin{array}{ll}\text { Priority: } & \text { High } \\ \text { Draft Report: } & \text { June 2004 } \\ \text { Final Report: } & \text { September 2004 } \\ \text { Approximate Cost: } & \text { \$90K }\end{array}$

\section{Task 2: Scientific Basis for Standard}

The purpose of this task is to provide a scientific basis for the proposed standard by looking at the pollutants (and indicators of exposure) that the standard will address and defining measures of acceptance for each. The sub-tasks will include,

- A review of studies measuring concentrations in homes similar to those expected to be constructed in the future

- A hazard assessment (See Appendix I for details) 
- Incorporation of the results from Task 1 and the results from the Characterization project

- A preliminary health benefits assessment (See Appendix I for details)

The outcome of this task will be a report documenting the objectives that could be included in an upgraded set of ventilation requirements in order to improve the quality of indoor air. (It is assumed that the characterization project will have produced a report substantiating the need for such requirements.)

$\begin{array}{ll}\text { Priority: } & \text { High } \\ \text { Draft Report: } & \text { September 2004 } \\ \text { Final Report: } & \text { December 2004 } \\ \text { Approximate Cost: } & \$ 160 \mathrm{~K}\end{array}$

\section{Task 3: Risk Assessment}

Whereas the purpose of Task 2 is to use simple IAQ and health criteria to form a broader scientific basis for the revised ventilation standards, Task 3 will rely on the more powerful techniques of risk assessment to take that result a step forward. (See Appendix I.) In order to complete this task, we will use existing information from EPA databases and the results of the previous tasks to set up an appropriate risk model.

The potential advantages of this approach are that we can use ventilation strategies to increase health protection and decreases energy impacts with lower costs. This results from synergies that become more obvious with the formal process of risk assessment, but are difficult to characterize based only on studies of hazard or hazard indicators. Furthermore, a formal risk assessment allows risk levels for different contaminants to be expressed in a consistent and transparent manner so that the Commission can make quantitative judgments about risk, costs, and benefits.

This activity uses an approach that is new to the ventilation field (even though risk-based standards have been around for three decades). To provide flexibility for the Commission to determine the appropriate level of detail to use in the risk assessment, the task is broken up into two subtasks, which will be carried out sequentially and each serve as a stand alone study with independent findings. At six month intervals the Commission can undertake a critical project review on this task to determine if further $R \& D$ is in the best interest of the State.

\section{Task 3.1 Formaldehyde Risk Assessment}

Make use of a full-scale risk assessment with formaldehyde to illustrate the use of risk assessment and to illustrate the trade-off between source control and ventilation.

$\begin{array}{ll}\text { Priority: } & \text { High } \\ \text { Critical Project Reviews } & \\ \text { and Interim Reports: } & \text { May, July 2004 } \\ \text { Final Report: } & \text { September 2004 } \\ \text { Approximate Cost: } & \text { \$60K }\end{array}$




\section{Task 3.2 Comprehensive Risk Assessment}

Assess the benefits of increased ventilation in terms of disease avoided. This can be related to costs of ventilation technologies and the costs of disease.

$\begin{array}{ll}\text { Priority: } & \text { Medium } \\ \text { Critical Project Reviews } & \\ \text { and Interim Reports: } & \text { June, December } 2004 \\ \text { Final Report: } & \text { June } 2005 \\ \text { Approximate Cost: } & \$ 50-180 \mathrm{~K} \text {, depending on progress and PIER decisions }\end{array}$

\section{Task 4: Options Analysis}

The previous tasks provide the tools to define the minimum performance requirements for ventilation systems in terms of IAQ. To build on this effort, this task provides the tools to analyze the various options that might be considered for meeting those requirements and addressing the key issues.

To complete this task requires simulation tools to evaluate source control and ventilation system options that might be adopted in the 2008 code. For any option considered, each key issue will be addressed, as appropriate and comparisons will be made.

The pros and cons for each option will be analyzed based on both qualitative and quantitative performance evaluations. We will then seek feedback on these results from affected parties.

$\begin{array}{ll}\text { Priority: } & \text { High } \\ \text { Interim Report: } & \text { December 2004 } \\ \text { Workshop: } & \text { February 2005 } \\ \text { Draft Final Report } & \text { April 2005 } \\ \text { Final Report: } & \text { July 2005 } \\ \text { Approximate cost: } & \$ 185 \mathrm{~K}\end{array}$

\section{Task 5: Health Studies}

In contrast to the hazard and risk assessment tasks, the goal of this task is to use field health studies to make direct links between health indicators and ventilation. The previous tasks rely on a systematic and stepwise effort to link sources, ventilation dilution, exposure and toxicological data to estimates of health burdens and potential health benefits. That is, ventilation requirements are established from the observation that sources emit contaminants, ventilation dilutes contaminant concentrations, concentrations impact IAQ, and IAQ impacts health. While this approach has a logical progression, there are a variety of complications that can limit the reliability of this chain of calculations.

In place of the prospective and deconstructed nature of risk assessments, many scientists in the health community prefer the evidence of health impact provided by retrospective or casecontrol epidemiological studies. These studies link health directly to measurable conditions as described in Appendix I. Because there are a variety of options to consider, specific sub-tasks are listed. 


\section{Task 5.1: Study Design}

This program of work has some very specific questions that could be answered from a health study such as those implied by the key issues. This sub-task would be used to further scope out what it would take to conduct such a health study and develop appropriate protocols.

$\begin{array}{ll}\text { Priority: } & \text { Medium } \\ \text { Draft Final Report: } & \text { June 2004 } \\ \text { Final Report: } & \text { September 2004 } \\ \text { Approximate cost: } & \text { \$85K }\end{array}$

\section{Task 5.2 Study Leveraging}

The CEC does not typically fund health-specific studies. The purpose of this task is to develop a consortium of interested organizations that are more inclined to support such health studies. CEC funds would then be used to leverage these studies to address questions of most importance to the CEC as described in the previous subtask

$\begin{array}{ll}\text { Priority: } & \text { Medium } \\ \text { Final Report: } & \text { TBD } \\ \text { Approximate cost: } & \text { \$200K }\end{array}$

\section{Task 5.3: Field Study}

If no partners are available, CEC could fund the field study directly and hope to reduce its commitment by bringing in cost-share partners after project initiation. The field study would be carried out according to the design from the first sub-task. Further task development work is needed before this activity can go forward.

Priority: Low

Semi-annual

interim reports

Final Report: Approximately 2006

Approximate cost: $\quad \$ 1000-2500 \mathrm{~K}$

\section{Task 6: Code Development}

In order to build on the previous tasks, which focus on the technical and scientific basis for a standard and the impact of various ventilation options, this task focuses on the process of developing the ventilation code. The efforts in this task include 1) gathering input from potentially affected parties 2) combining that input with the technical analyses to develop recommendations for changes to Title 24,3 ) working with code compliance interests to facilitate implementation should it be adopted and 4) to assist the Commission during the public process.

In spring or summer of 2004 a workshop of interested parties will be held to better understand the needs and concerns of affected parties. At this workshop key issues will be presented and discussed. 
After a critical project review the recommended code changes will be presented to the Commission in June 2005 for possible inclusion in the 2008 standards. Efforts will continue after that point to complete final reports. Effort is included in the proposed budget to make presentations, attend hearings and do a limited amount of follow-on analyses should questions be raised during the public process.

$\begin{array}{ll}\text { Priority: } & \text { High } \\ \text { Interested Parties Workshop: } & \text { June 2004 } \\ \text { Memo report on status of and } & \\ \text { barriers to code changes: } & \text { February 2005 } \\ \text { Proposed Code Changes: } & \text { June 2005 } \\ \text { Status Report on follow-on activities: } & \text { December 2005 } \\ \text { Approximate cost: } & \$ 175 \mathrm{~K}\end{array}$

\section{TECHNICAL PUBLICATIONS}

Although not specifically described in the list of deliverables, we expect that each R\&Doriented task (i.e., Tasks 1-5) will result in at least one peer-reviewed publication in the appropriate scientific literature. These technical publications and any presentations associated with them are intrinsic parts of the technology transfer associated with this research.

\section{LINKAGE BETWEEN PROJ ECT GOALS AND RESEARCH PLAN}

The key issues addressed earlier cross all of the tasks listed in the research plan and are not, therefore, specifically addressed in the text. It must be understood, however, that for each task, the key issues need to be reviewed and addressed. In the course of conducting this research, unanticipated issues may arise and must be confronted. Therefore, some level of project review and oversight is necessary and is included in the administrative task.

The other tasks in the research plan mirror the objectives of the project as outlined in earlier sections. But because of the need for overlap among the tasks, there is not a one-to-one correspondence among the tasks and the objectives. Several tasks address specific objectives in some way, while most objectives require results from more than one task to be complete. In the remainder of this section we address the linkage between the research plan and the objectives of the project:

\section{Define Indicators and Contaminant Sources of Concern}

Two types of sources need to be evaluated to define the contaminants and other indicators of concern: 1) existing guidelines and engineering estimates and 2) the scientific literature.

The results of task 1 will provide a list of the indicators and/or contaminants that are currently used in codes, guidelines, or standards on IAQ. The review of the literature in task 2 may further expand this list based on measured exposures in indoor environments. In addition, early results from the related characterization work will also be included.

Based on the hazards assessment approach in task 2, the list of possible indicators and especially contaminants of concern will be winnowed down and prioritized. 


\section{Determine Acceptance Criteria}

Once an indicator or contaminant is determined to be of concern, it is necessary to develop and apply acceptance criteria. For some contaminants this criterion can be a concentration, for others it can be the presence or absence of a source or a control technology.

The reviews that are the output of tasks 1 and 2 will provide acceptance criteria for some of the indicators and contaminates directly. For others it will be necessary to develop acceptance criteria by analyzing published data and extrapolating to the concentration regimes of interest as needed.

Our scientific analysis of acceptance criteria will be based on using thresholds and similar limits determined by cognizant authorities and the appropriate peer-reviewed publications. The results of this method of determining acceptance criteria will be included in the report that is the output from task 2 .

Our proposed method of determining acceptance criteria is a low-risk approach and can reliably be expected to reach a resolution in the time frame necessary for the 2008 standards. There are two other methods of developing acceptance criteria that have the potential to be of great benefit to California, but are higher risk approaches. The two approaches are risk assessment and health studies.

The risk assessment approach is included in task 3 . Rather than employ a binary acceptance criterion such as an exposure threshold, the risk assessment approach uses outcome data to develop a level of risk for any exposure profile. The advantages of such an approach are that it allows greater flexibility and it allows risk from different sources and from different pathways of exposure to be compared. (See Appendix I for a more detailed discussion.)

In the regulatory community, risk assessment is a mature and now standard tool for setting exposure limits, but it has not yet been applied to the problem of setting ventilation standards. As task 3 progresses, acceptance criteria may be modified to incorporate the results from risk assessment. The results of task 3 might also be used to evaluate ex post facto any standard development. We expect the risk assessment to provide valuable insight to and be important in further improvements of the standard.

In contrast to a risk assessment that establishes a quantitative relationship between dose acceptability and exposure to some contaminant or source, the health-studies approach does not presuppose an explicit mechanistic link. Instead, the health-studies approach requires field data directly linking health outcomes to properties of the building such as sources and ventilation rates. Because of the time span associated with such large field studies, it is unlikely that results of the health study would impact the 2008 standards-development process, but such health studies must be started soon to have any impact on the 2011 standards.

\section{Set Source Control Requirements}

Source control requirements for many sources can be and have been set from an engineering basis using professional judgment. In the report of task 1 will provide a review of existing guidelines and a summary of conventional source control measures. However, to fully achieve the objective of setting source-control requirements, we must go beyond existing guidelines to 
establish a more scientifically rigorous basis for different source control requirements. This will be achieved using the acceptance criteria that are derived in tasks 2 and 3 .

Using scientifically defensible acceptance criteria in this way will provide both robustness and flexibility to the standards development process. It will lead to a variety of different source control options that can achieve the same objective. It will provide insight on trade-offs among the amount of a material or process, its specific source strength, local removal (e.g., exhaust fan) and whole-building ventilation rates.

This particular objective can be greatly enhanced by the level of success in obtaining results for task 3. Moreover the robustness and flexibility of the process will be further enhanced by results from a defensible risk assessment. Greater flexibility makes possible strategies that can lower costs, lower energy use, and improved indoor environments.

\section{Set Minimum Ventilation Rates}

Minimum whole-house ventilation rates can be and have been set on an engineering basis using professional judgment. In the report of task 1, there will be a review of existing guidelines and a summary of recommended minimum ventilation rates. However to fully achieve the objective of setting minimum ventilation rates appropriate for California, we need to go beyond existing ventilation rate data to look for a more rigorous basis for setting these minimum rates. The acceptance criteria that are derived in tasks 2 and 3 will be key inputs for meeting this objective.

As was the case for source control, the use of scientifically defensible acceptance criteria provides both robustness and flexibility in addressing ventilation needs. In particular, our process will explicitly address trade-offs between local (single-room) and whole-building ventilation rates. For each set of source requirements there may be a different whole-building ventilation rate that is appropriate.

It is important to have the flexibility to consider trade-offs between source control and ventilation needs. For example, the minimum ventilation rate can be set based on the key contaminant of concern. Once a minimum ventilation rate is set, it will be possible to examine the option of reducing or enhancing some source-control requirements. The optimal solution then requires an iterative approach, which is the purview of task 4.

\section{Evaluate Costs \& Benefits}

There are many combinations of whole-house ventilation and various source requirements that could in principle meet all important acceptance requirements, but there are other key issues to address such as first cost, energy impact, etc.

Evaluating the associated costs and benefits of different options is the primary focus of task 4 , which will consider the various ways of providing acceptable IAQ. The economic principle of pareto optimality can eliminate some options, but the report of task 4 will undoubtedly provide multiple packages that could be used as new standards

\section{Technology Transfer and Research Implementation}

To narrow the options for source/ventilation requirements to a single set of requirements involves more than a scientific evaluation of the key issues; it requires working with the CEC and interested parties. Task 4 will generate options for the new standards, but task 6 will 
focus on narrowing and fine-tuning those options to meet the many public and private interests of the State.

In addition to providing input to the team, the workshops and reviews of task 6 will also serve the function of getting information to groups that might be able to use it to begin to change what they do and how they do it.

The results of task 5 and/or any $2^{\text {nd }}$ phase characterization efforts should provide preliminary but useful results at the time of public hearings on the standard. These results will be beneficial in providing corroboration to the analyses of tasks 1-4. More importantly, perhaps, such data will be necessary within that timeframe for the next round of standards and to provide input to PIER for future research planning efforts.

Finally, tasks 1-5 will generate archival technical reports (as well as CEC reports) that will go into the wider scientific literature. This provides a platform for future PIER work and also serves as a demonstration of the quality of PIER-funded research.

\section{SUMMARY}

Our preliminary review indicates that it is feasible and advisable to modify the residential ventilation requirements in Title 24 in time for the 2008 standards cycle. This modification should be based on a well-focused research program that confronts the problems of incorporating health considerations in ventilation standards. We have identified five research goals for this project: 1) define contaminants and sources of concern, 2) determine acceptance targets for these contaminants, 3) set source control requirements, 4) set minimum ventilation rates, and 5) evaluate costs and benefits. We have identified a number of key issues that must be addressed in this research including adventitious air flow; infiltration; duct leakage; flues, stacks, vents, and chimneys; air distribution; code compliance; filtration and air cleaning; particle filtration and HVAC systems; occupant acceptability and control; sensitive populations; outdoor air; time dependent valuation; unusual sources and high-polluting events; and window operation. To achieve the research goals and address the key issues we have proposed the following tasks: 0) administration 1) analysis of existing ventilation guidelines, 2) develop the scientific basis for guidelines, 3) risk assessment, 4) options analysis, 5) health studies, and 6) code development. For each task we have established research priority, estimated costs, set timelines and discussed likelihood for success. 


\section{The Advantages and Limitations of Using Health Assessments in Ventilation Standards}

Current Title 24 ventilation standards are not directly based on health, but use engineering judgment. However, a large body of research over the last two decades has established that ventilation is an important factor impacting exposure to indoor pollutants. Emerging studies provide an opportunity, to consider the impact of ventilation on exposure and health. For example Assembly Bill 1173, which the Governor signed into law in September 2002, requires the Air Resources Board to compile a comprehensive report on indoor air pollution. Among the topics that must be addressed in this report are the health effects and sources of indoor pollutants; the effects of existing regulations and industry practices; and possible mitigation options for homes, schools and non-industrial workplaces. Although there are clear opportunities and benefits for using health protection as an explicit basis for setting ventilation standards there are also clear limitations and risks. Among these limitations are large uncertainties in the links between exposure and disease at low dose rates, the lack of consensus about setting acceptable levels of exposure, and the need for making trade-offs among health benefits and cost, feasibility, energy use in applying ventilation standards.

In this Appendix to the scoping report we describe and evaluate four types of studies that could be used for incorporating health benefits into ventilation standards. These are hazard assessments, risk assessments, health surveillance studies, and health benefit assessments. We begin here with an overview of what is currently known about indoor-air quality and health. Then for each of the four alternative approaches for incorporating health information in future standards we assess capabilities and limitations. This evaluation includes research costs, likelihood of success, impact and practicality.

\section{Health Perspective}

To those interested in improving the health of Californians the goals of this scoping study are to (1) consider what research is needed to strengthen health-based residential ventilation requirements for Title 24; (2) examine whether available and emerging knowledge about ventilation and indoor air quality could support these requirements and (3) assess the risks, costs, and likelihood of success for this approach. This scoping study is intended to support PIER efforts to develop a research plan to advance the standards.

The purpose of ventilation is to provide acceptable indoor air quality, to enhance durability of systems and materials and to reduce direct (acute) health impacts. Health scientists have long recognized that ventilation and indoor air quality are potentially linked to chronic illness. Current Title 24 standards for building ventilation are primarily engineering based. Technical feasibility is a key driver for these standards. In contrast to other residential environmental media, such as tap water, indoor air has not been the subject of mandatory standards. However, the US EPA has set standards for Radon, the California Air Resources Board has indoor air quality guidelines, and the Canadian government issued guidelines for many indoor pollutants as early as 1987 (Health Canada, 1995). An important consideration for all future ventilation standards is the feasibility of making human health protection an explicit goal rather than relying only on a simple engineering consensus approach. However, there are potential costs and risks associated with the use of health-based standards that must be evaluated as part of 
this process. In particular, the reliability with which the health benefits of ventilation can be characterized. In order to support the Title 24 process, CEC must determine whether and how ventilation-related requirements could be based on a quantitative health risk assessment or other health studies. For this there is a need to document how ventilation requirements could impact contaminant concentrations and quantify the effect those contaminant concentrations have on health. This requires an effort to consider existing and new information about the relationships of pollutant concentrations to human-health outcomes. With these issues as motivation, this Appendix outlines the technical issues that must be investigated to facilitate explicit consideration of health in ventilation. We then examine the magnitude and scope of the $R \& D$ that would be required to provide an adequate basis to include health considerations in building energy standards.

\section{Indoor Air Quality and Health}

Indoor air quality is an important environmental health concern because the average person spends more than $90 \%$ of his or her time indoors. A number of studies have established the link between indoor-air pollutants and health. Most of these studies use hazard or risk assessment. In a 1987 study, the U.S. Environmental Protection Agency (EPA, 1990) ranked indoor air pollution fourth in cancer risk among the 13 top environmental problems analyzed. Indoor air quality studies have found recurring correlations between indoor air pollution and human illness. Research by the ARB, the EPA, and others has shown that indoor levels of some pollutants, such as formaldehyde, chloroform, and styrene, range from 2 to 50 times higher than outdoor levels.

Adequate ventilation is an easy and effective way to maintain good indoor air quality, although it may not completely remove all pollutants. Inadequate ventilation can increase exposures to indoor air pollutants, while increased ventilation decreases exposures. The California Air Resources Board has published health-based IAQ guidelines for California homes. But currently, there are no federal, state, or local regulations or guidelines that explicitly address the role that ventilation plays in meeting these standards. When weather permits, occupants can increase ventilation by opening windows and doors. This strategy is particularly important when using products or engaging in activities that may generate pollutants. Kitchen and bathroom exhaust fans that are properly vented to the outdoors are very effective at removing pollutants generated during cooking and showering.

There is a wide array of potentially available information that can be used for characterizing potential and actual exposures to indoor pollutants, including data on indoor emissions, concentrations measured in the residential environment, personal exposure modeling, and levels of chemicals in the human body (biomonitoring).

\section{Sources of Indoor Air Pollution}

Pollutants enter the indoor environment of residences as the result of interaction among the site; climate; building systems; construction materials and techniques; contaminant sources including moisture, processes and activities within the building, and outdoor sources; and building occupants. Indoor air contaminants can originate from within the building or be drawn in from outdoors. If contaminant sources are not controlled by ventilation or some other removal process IAQ problems can arise. In applying health-based approaches to setting ventilation standards by any of the procedures outline below, it is important to sort out sources and types of indoor contamination according to which sources have exposures most likely to 
be reduced by changes in ventilation methods. For this reason we divide pollutant sources to residences into the following categories:

\section{Outdoor Sources}

In almost all inhabited enclosed spaces, there is a continuous exchange of air with the outside. Therefore, all contaminants of outdoor air are likely to be present indoors. Important pollutants in this category include carbon monoxide, oxides of nitrogen, oxides of sulfur, particulate matter, ozone (and other photochemical oxidants), and lead. These pollutants originate, to a large extent, from automobile and factory emissions and other combustion processes. Generally, in the absence of indoor sources of these contaminants, concentrations indoors will be close to or lower than those outdoors. But modifications to household ventilation systems can be used to further reduce indoor levels relative to outdoor levels.

Radon-222 enters homes from underlying soil and domestic well water. Other soil and ground water contaminants such as are found in shallow ground water or near landfills can enter homes from underlying soil or water supplies.

\section{Indoor Sources}

Internally generated airborne pollutants fall into one of three categories:

- those formed in combustion processes for heating and cooking;

- those derived from construction materials and furnishings;

- those related to human activity or presence.

Concentrations of contaminants in the first and last categories tend to vary with time; those in the second are likely to be more constant, as long as air exchange rates remain constant.

Furnaces, wood-burning stoves, and other combustion appliances can be sources of indoor pollutants, notably carbon monoxide, especially if they are not properly vented or routinely serviced. Though by-products should be vented to the outside, leaks and improper operation of these appliances can cause emissions to the indoors. Contaminants associated with woodburning stoves and fireplaces include carbon monoxide, oxides of nitrogen and sulfur, aldehydes and polycyclic aromatic hydrocarbons. A major potential source of combustion byproducts is gas-fired stoves. If emissions from the oven and pilot light are not vented, they can contribute to indoor levels of carbon monoxide, nitrogen oxides and formaldehyde. Candles are a significant source of fine particulate matter.

Building materials, consumer products, home furnishings, and home pest treatments can be significant sources for several indoor pollutants. Formaldehyde is released from wood laminates and particle board in which formaldehyde-containing resins have been used. Ureaformaldehyde foam insulation is a significant source of formaldehyde and possibly other gaseous products. Synthetic polymers used in furnishings and decorative materials can slowly degrade, releasing small quantities of the original constituents or reaction by-products. Draperies, rugs and fabrics that contain man-made fibers are sources of a variety of organic, and potentially microbiological, contaminants. Fibrous materials such as asbestos and fibrous glass are present in some building materials and may be released to the indoor environment especially when such products are disturbed during building alterations. A number of pesticides including wood treatments, pet collars, and chemicals for the control of mold and 
mildew bring chemicals such as organophosphates and synthetic pyrethroids into the residential environment. Air fresheners, furniture waxes, polishes, cleansers, paints, fabric protectors, deodorants and other products frequently used in the home are sources of various inorganic and organic chemicals. Many substances found in the workplace may also occur in the home as a result of hobby or craft activities. Moreover, workers exposed to chemicals in the workplace may bring these contaminants into the home on their clothing (this has been documented for farm workers and dry-cleaning workers).

There are also a variety of contaminants that result from specific activities of the occupants of a residence. Tobacco smoking is a major source of indoor air pollution. Respiration, perspiration and food preparation add water vapor as well as odor-producing substances to the indoor atmosphere. 


\section{TYPE 1: Hazard Assessment}

Hazard is the potential for harm. Hazard assessment involves information on indicators that correlate with the potential for exposure and disease. In applying hazard assessment we use available data on sources, emissions, exposure potential, and toxicity data to define and rank pollutants of concern. The objective of this task is to provide a transparent and easily implemented process to summarize and apply existing knowledge about relationships between ventilation rates and potential health outcomes to California housing. Figure 1 illustrates the steps needed to conduct a hazard assessment in support of the relative impact of ventilation among a set of indoor air pollutants. Because the hazard assessment process is primarily qualitative, it does not have the information demand of more sophisticated studies such as risk assessment or health studies. As illustrated in Figure 1, the goal of a hazard assessment is to construct set of hazard indicators from three factors for each pollutant-a indicator of the relative magnitude of this pollutant's concentration in indoor air, a measure of toxicity, and a qualitative score of how ventilation impacts (increases or decreases) indoor levels.

$\begin{array}{ccccc}\text { Pollutant } & \begin{array}{c}\text { Estimated or } \\ \text { Observed } \\ \text { Concentration } \\ \text { name }\end{array} & \begin{array}{c}\text { Measure of } \\ \text { toxicity }\end{array} & \begin{array}{c}\text { Impact of } \\ \text { ventilation }\end{array} & \begin{array}{c}\text { Overall measure } \\ \text { of hazard }\end{array} \\ & \mathrm{Xmg} / \mathrm{m}^{3} & \begin{array}{c}10 \mathrm{Xmg} / \mathrm{m}^{3} \\ {[\mathrm{safe} \text { dose }]}\end{array} & \text { High, low, etc } & \text { Low }\end{array}$

Figure 1 Example of the approach used to rank indoor pollutants by the relative impact of ventilation

A hazard-indicators study requires data on emissions and/or measured levels of indoor pollutants found in California homes. Such data is available from LBNL and the Air Resources Board. This approach also requires measures of relative toxicity. For most indoor pollutants such data are available from the US EPA Integrated Risk Information System (IRIS) to relate indoor pollution to measures of hazard. The hazard assessment process can be applied to a large number of potential indoor pollutants. We can use the hazard characterization to identify a subset of pollutants of concern as candidates for more comprehensive risk characterization.

Since the EPA first issued cancer and mutagenicity risk assessment guidelines in 1986 (EPA 1986a), there have been advances in both the types and reliability of methods used to identify potential hazard. In the 1986 guidelines, the stated goal of a hazard assessment was to provide a review of the relevant biological and chemical information bearing on whether or not an agent may pose cancer or other health hazards. The arsenal of methods, the reliability of techniques, and the relative emphasis on the various hazard identification elements have increased over the last decade (NRC, 2002). There have been recent efforts to development more sophisticated measures of hazard such as the human toxicity potential (Hertwich et al., 2001), which includes emissions, exposure potential, and toxic hazard indicators in a single measure of potential harm. The human toxicity potential has been used as a cumulativeexposure screening tool for multiple chemical agents. Also in the last decade hazard identification methods for biological agents have been introduced (NRC, 2002). In the following paragraphs, we consider the research costs, likelihood of success, impact and practicality of using hazard assessment as a tool to support health-based ventilation standards. 


\section{Research Costs and Level of Effort}

Much of the information need to construct a hazard assessment is readily available. The information needed to construct a Table such as that shown in Figure 1 could be assembled in a matter of months. The most difficult aspect of this effort would be developing indicators of how ventilation impacts likely exposure. We estimate that the cost of a simple effort would involve three to six person-months of labor.

\section{Likelihood of Success}

Because this approach requires little in the way of measurements and new information the likelihood of success is high.

Impact

The impact is likely to be quite low relative to more detailed health effects studies. Hazard indicators show trends and possibilities but cannot be used to assess the likely change in disease burden. However, if the ventilation standards are based primarily on engineering judgment and moisture control, the hazard assessment provides a useful adjunct for assessing likely impacts on health. Hazard assessment can be used to identify a subset of pollutants of concern as candidates for more comprehensive risk characterization or health surveillance studies.

\section{Practicality}

There is an extensive literature on hazard assessment, hazard tracking, and applications for establishing hazard indicators. The relatively low level of effort required and the ready availability of hazard information makes it quite practical for CEC to develop a set of hazard indicators for the potential impact of ventilation on a number of indoor pollutants. 


\section{TYPE 2: Risk Assessment}

Risk assessment is a process for identifying potential adverse health consequences along with their severity and likelihood. The risk assessment/management approach differs from other environmental protection strategies in that its principal objective is not to eliminate all risk but to quantify the risk and provide policy makers with tools to balance the level of risk against the cost of risk reduction, against competing risks, or against risks that are generally accepted as trivial or acceptable. Controlling the exposure of human populations to indoor exposures using a risk-based approach requires that we define an appropriate metric for assessing the impacts of contaminants on human health. For making cost assessments, we may also need a defensible process for assigning value to the predicted impacts. The end product of a riskbased approach to environmental management is either to identify an acceptable level of exposure or prescribe a required level of intervention, such as source control or ventilation.

A risk assessment has five principal elements-(1) quantification of sources and of concentrations in indoor air; (2) quantification of exposure and doses to the target population and how the dose is distributed among the population; (3) quantification of a dose-response function for contaminants of concern; (4) estimates of the numbers and severity of consequences expected within the population at risk; and (5) an assessment of the magnitude and sources of uncertainty that limit the precision of the estimate of consequences. We show the flow of information for these elements in Figure 2 along with an indication of where ventilation fits in this scheme.

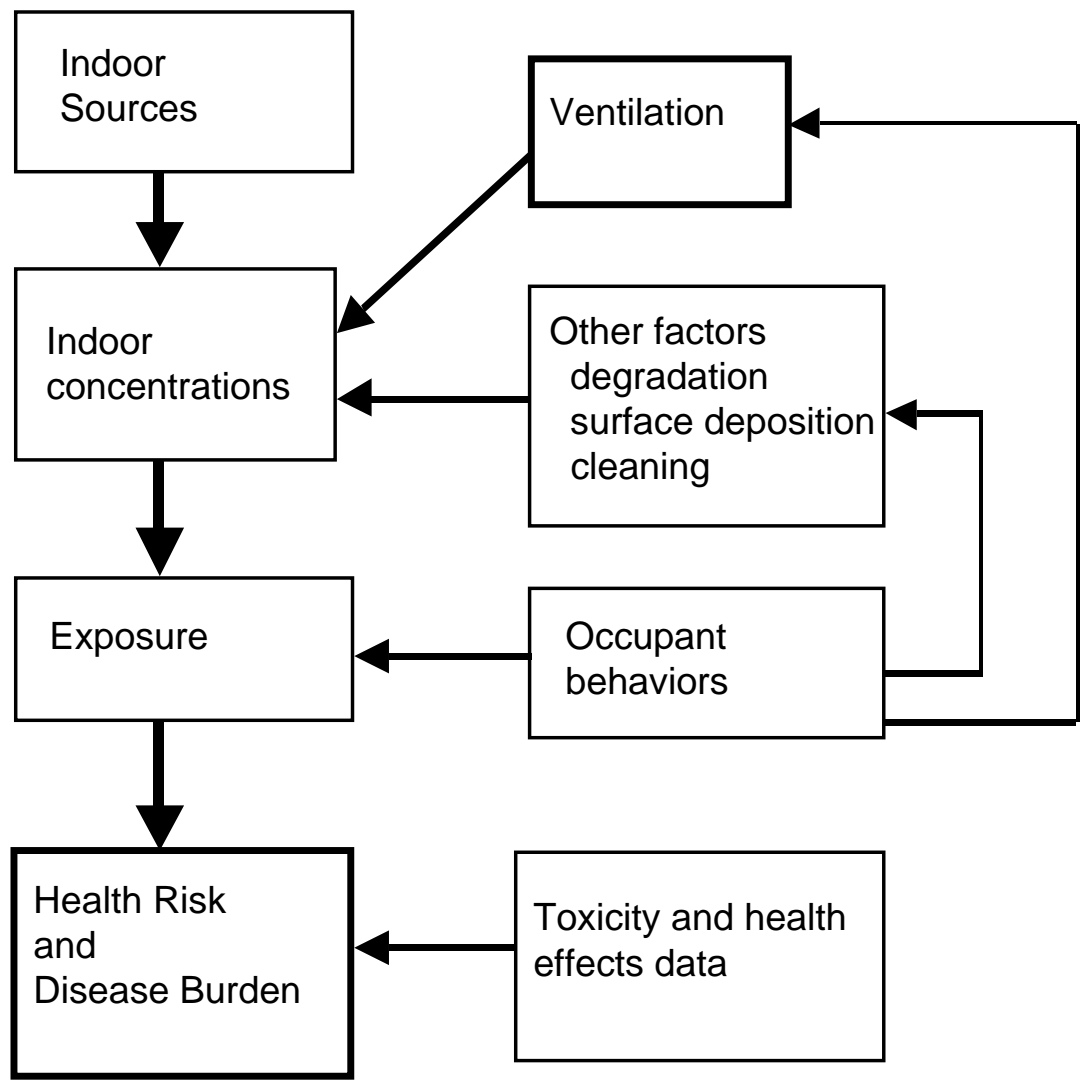

Figure 2 A schematic diagram of the flow of information in the risk assessment process applied to indoor pollution and identifying the role of ventilation. 
In contrast to the hazard assessment process described above, the risk characterization is used to establish the significance of an identified hazard by quantifying the likelihood and severity of exposure scenarios linked to that hazard. For evaluating the link between ventilation and health we must identify a set of contaminants of concern. We expect that the hazard assessment process described above can be used for this step. We then use a formal risk assessment to estimate the burden of acute and chronic disease attributable to each indoor contaminant source and how this relates to ventilation. The risk assessment will be used to characterize the significance of each contaminant of concern by quantifying the likelihood and severity of exposure scenarios linked to that contaminant. Through this process we relate sources and exposure to disease burden.

Whole-house ventilation rates are only part of the set of requirements intended to protect or enhance indoor environmental quality. The first mechanism for reducing risk is source control. There are various ways to effect source control. Elimination of an activity (e.g., unvented combustion) is the most straightforward method of source control, but when an activity is intrinsic to the operation of a home (e.g., cooking, bathing), source control can be provided using techniques such as local exhaust or direct venting. Material emissions can be controlled either by reformulation, reduction of the use of high-polluting materials, or encapsulation. Whole house ventilation should normally only be relied on to dilute contaminants when source control is impractical, however, trade-offs can sometimes be effectively made.

\section{Research Costs and Level of Effort}

In contrast to the hazard assessment process, risk assessment requires a greater level of effort for assembling information and carrying out the actual risk assessments. Risk assessment requires more detailed information about sources and a more complex assessment of human activities and exposure. Moreover, it requires an effort to obtain and apply dose-response functions. However, one advantage of the risk-based approach is that it is typically based on available information and does not require field studies or surveys. Much of the information needed for assessing the risks of a broad set of indoor pollutants is readily available. The US EPA and California ARB as well as LBNL have compiled extensive data on the chemical sources to the indoor environment. The US EPA as well as the ARB have developed detailed information on time-activity budgets as well as extensive computer models to use this data to assess exposures. The US EPA has developed and made widely available the data and software needed to construct dose-response functions for almost all pollutants of concern in the indoor environment. However, assembling and applying this information for the express purpose of assessing risk in a range of California homes will involve a level of effort of some one to three person-years.

\section{Likelihood of Success}

The likelihood of success is high. Most of the information needed for the risk assessment is readily available or currently emerging, that is emissions data, occupant activity data, measurements of pollutant levels in homes, and dose-response data for all the pollutants of concern. Moreover, there is an extensive literature on risk assessment methods. The US EPA's National Exposure Research Laboratory has two risk assessment models, EXPOSE and SHEDS that have been developed explicitly for assessing indoor exposures and health risks in residential environments. The ARB also has software and data developed explicitly for assessing risk. But it must be recognized that there has to date been no comprehensive risk assessment addressing cumulative impacts from multiple indoor pollutants and how these risks relate to ventilation. Such cumulative risk assessments have been carried out for pesticide exposures so there is a president from which to work. But since this would be the first effort to consider risks from multiple indoor pollutants across the population of California, its success 
would be dependent on an adequate commitment of research funds and strong scientific leadership.

\section{Impact}

Throughout the US, Europe, and Asia risk assessment studies have been used to support policies and actions taken to protect health. Results of risk assessments have high and growing credibility among policy makers. But the impact of a risk assessment will always be limited by the fact that risk assessments are predictive studies. There are important sources of uncertainty/variability in risk assessments that involve the use of large amounts of data coupled with the use of models. Because these data and models are based on incomplete data and represent heterogeneous geographic and climate regions, there is large variability and uncertainty associated with the resulting risk estimates. These uncertainties and the inability to confirm the results of risk assessments can work to limit their impact.

\section{Practicality}

Since research into the health effects of residential indoor air quality is at an early stage, there is a dearth of reliable information on the health effects that result from exposure to the low levels and mixtures of contaminants likely to be found. For most chemicals of concern, we will need to rely for health effects studies on the results of laboratory experiments using animals, clinical studies with human volunteers, and epidemiological investigations of urban air pollution and the occupational environment. Although this is common practice in risk assessment and results of animal studies are widely available, there is a continuing question about the relevance of laboratory animal studies, limited clinical studies, and occupational studies for assessing low-dose exposures in residential indoor environments. 


\section{TYPE 3: Health Studies}

Health studies include epidemiological and clinical studies and provide both alternatives and adjuncts to risk and hazard assessments.

Epidemiological studies of populations exposed to indoor pollutants can be classified as observational or non-experimental studies and intervention or experimental studies. In observational studies, the allocation of individuals into study groups on the basis of exposure is not under the control of the investigator. Observational studies can be further classified as descriptive (cross-sectional) or analytical (cohort or case-control) studies. In cohort studies, exposure and outcome are monitored over time; as a result, the quality of evidence obtained from such longitudinal investigations is generally considered to be superior to that from crosssectional studies, in which populations are monitored at one time. However, the results of all observational studies must be evaluated against the quantity and quality of exposure data and the need to address confounding factors. Observational epidemiological studies considered most relevant for developing indoor exposure guidelines should include a longitudinal study design; adequate control of appropriate confounding factors; and efforts to take individual variations in exposure into account. Experimental-epidemiological studies such as multi-home intervention studies should also be considered as relevant studies for developing indoor exposure guidelines.

Clinical studies are generally, though not always, conducted in controlled laboratory environments. These studies probably provide the most reliable data from which to derive exposure-response relationships that form the basis for air quality standards. However, clinical studies are restricted for ethical reasons to the examination of mild, temporary effects of shortterm exposures in a limited number of subjects. As such, they are most suitable for developing short-term exposure limits.

\section{Research Costs and Level of Effort}

To provide reliable information, health studies require large numbers of participants. Designing and conducting a health study that specifically addresses exposures and health status in relation to ventilation requires a large level of effort-as much four to five person years. As an alternative, we could make use of existing epidemiological studies that have considered the link between ventilation and health. This would reduce the cost and level of effort. However, currently available studies linking ventilation and health are for work-place exposures and could lack relevance for residences and residential populations.

\section{Likelihood of Success}

Epidemiological studies are structure around a premise, i.e. the link between a disease outcome and health. Often these studies refute or confirm the premise, but do not always establish the quantitative link needed to support standards setting. The same applies to clinical studies. The likelihood of success in using health studies is high for demonstrating a link between ventilation and health, but low for demonstrating the magnitude or slope of this relationship for a number of disease endpoints. 
Impact

In contrast to hazard and risk assessment studies, health studies have a large impact on health scientists, policy makers, and members of the public. This is clearly a key advantage of these types of studies.

\section{Practicality}

Health studies are practical for assessing the link between ventilation and health consequences that are acute-headache, fatigue, allergic reactions etc. To the extent that these endpoints are markers for chronic disease, they can be used to suggest the impact on chronic disease endpoints. However, epidemiological studies and clinical studies are not practical for assessing the link between ventilation and chronic diseases such as cancer. 


\section{Benefits Assessments}

Any studies used to support decisions about ventilation requirements will involve both implicit and explicit trade-offs among energy costs, construction costs, and the valuation of disease burden. Thus, the CEC must recognize that if they use health protection as a criterion for setting ventilation standards, they need to engage in some process of benefits assessment. There are four types of analyses that are commonly used to assess trade-offs among competing actions-cost-benefit, risk-benefit, risk-risk, and cost-effectiveness analyses (McKone, 1996). A cost-benefit analysis relates the financial cost (in dollars) of reducing risk to the benefits (in equivalent dollars or an appropriate surrogate) gained by reducing risk. A riskbenefit analysis provides a comparison of the risks added by an activity to the concurrent benefits (usually economic) provided to society. A risk-risk analysis establishes the significance of an estimated risk by comparing it to some other acceptable or familiar risk such as those associated with background exposures, household accidents, occupational hazards, natural occurrences, etc. A cost-effectiveness analysis is use to compare risk reduction per unit cost among several options for dealing with the same risk.

\section{Research Costs and Level of Effort}

Once levels of hazard or risk and a range of technologies have been established, the benefits analysis can be carried with a relatively low level of effort, on the order of 1-2 person-year or less.

\section{Likelihood of Success}

The likelihood of success for benefits assessment depends on the ready availability of information on hazard or risk and the cost of different ventilation technologies. If these are readily available the likelihood of success is high. Methods for benefit analysis are widely available, well established, and straightforward.

\section{Impact}

Benefits assessments are useful for addressing the critical trade-offs raised by competing interests in the standard-setting process.

\section{Practicality}

Benefits assessments require some key assumptions about the valuation of health and disease. These are sometimes controversial and frequently challenged by special interests. But even if CEC does not carry out an explicit benefits assessment, it is highly likely that some organization will. So it is an advantage to CEC to have a benefits assessment in place to address any benefits-based challenge to the proposed ventilation standards.

\section{Findings and Recommendations}

Indoor air quality and resulting occupant exposures and risks depend on pollutant sources, pollutant transport, ventilation, and occupant behavior. Because the health burdens of indoor 
pollution are directly linked to ventilation, the CEC exposes itself to a significant risk if it fails to explicitly address this link in establishing ventilation standards. However, CEC also faces risk in attempting to rely primarily on health benefits to set ventilation requirements in Title 24 .

We have identified four types of health-based studies that can be used to evaluate the link between residential ventilation and health. These are hazard assessment, risk assessment, epidemiological or clinical health studies, and benefits assessment. These studies provide the CEC with a number of alternative tools for assessing how different ventilation standards could impact health. These tools are not independent or mutually exclusive. Each has capabilities and limitations with regard to cost/level-of-effort, likelihood of success, impact and practicality. The limitations we identify here indicate that it will be difficult to base ventilation standards primarily on health protection. But the capabilities of these tools suggest that the link between ventilation and disease can and should be considered in the standards process through some combination of these assessment tools. 


\section{APPENDIX II: List of Energy Codes by State}

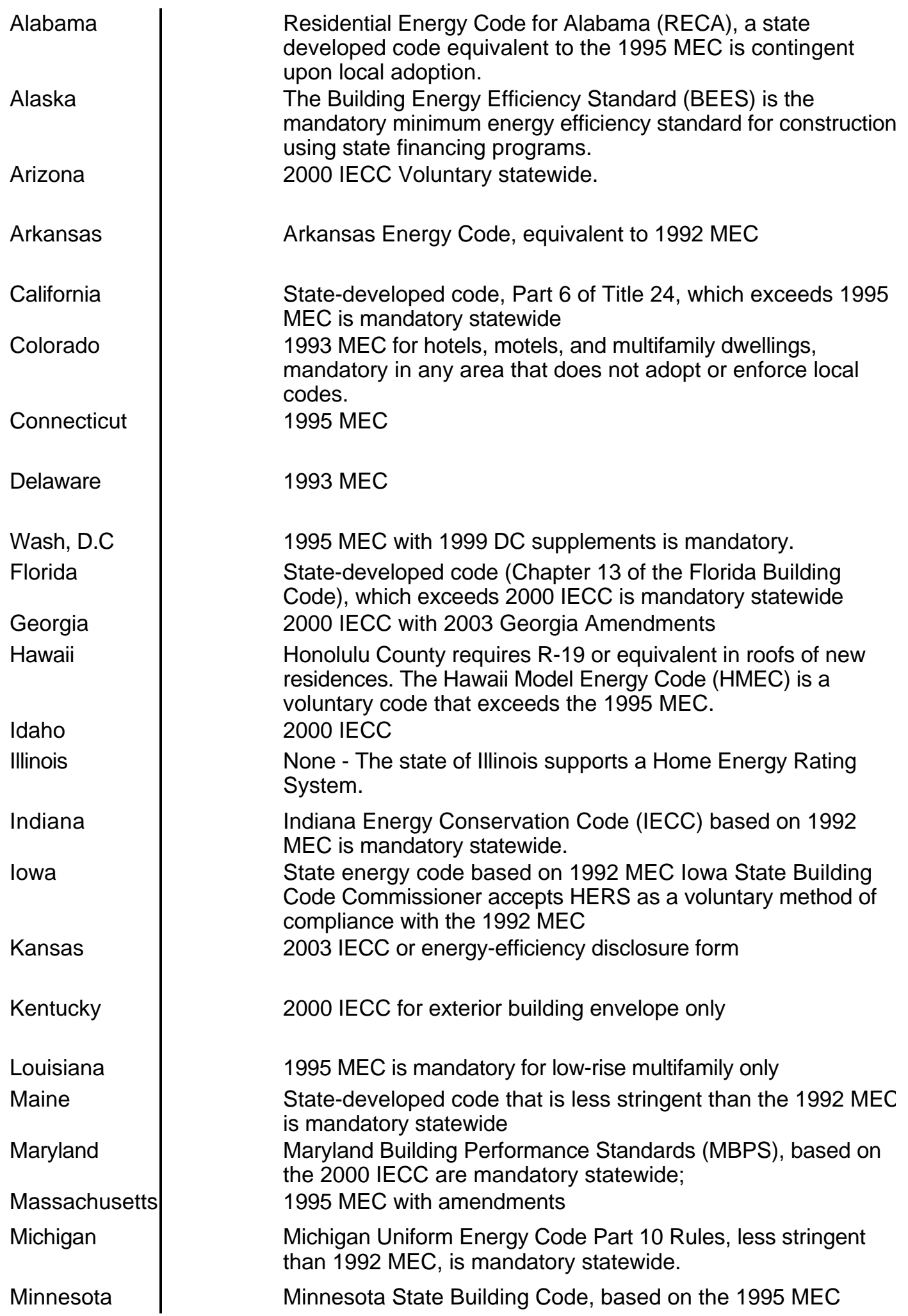




\begin{tabular}{|c|c|}
\hline Mississippi & $\begin{array}{l}\text { State energy code, based on ASHRAE Standard 90-1975, is } \\
\text { adopted by local jurisdictions. }\end{array}$ \\
\hline Montana & $\begin{array}{l}\text { None statewide. State-owned single-family and multi-family } \\
\text { residential buildings must comply with the latest edition of the } \\
\text { MEC or ANSI/ASHRAE Standard 90.2-1993. } \\
1993 \text { MEC with state amendments }\end{array}$ \\
\hline Nebraska & $\begin{array}{l}\text { For conventionally funded projects: } 1983 \text { MEC is mandatory } \\
\text { statewide. State-owned and -funded buildings must comply } \\
\text { with } 98 \text { IECC. }\end{array}$ \\
\hline Nevada & 1986 MEC with state amendments \\
\hline $\begin{array}{l}\text { New } \\
\text { Hampshire }\end{array}$ & 2000 IECC \\
\hline New Jersey & 1995 MEC is mandatory statewide \\
\hline New York & 2001 IECC w/amendments. \\
\hline North Carolina & $\begin{array}{l}\text { State-developed code, modeled on the } 2000 \text { IECC with } \\
\text { amendments }\end{array}$ \\
\hline North Dakota & $1993 \mathrm{MEC}$ is contingent on adoption by local jurisdiction \\
\hline Ohio & $\begin{array}{l}\text { Chapter } 13 \text { of the } 2002 \text { Ohio Building Code; } 2000 \text { IECC } \\
\text { w/2001 supplement }\end{array}$ \\
\hline Oklahoma & $\begin{array}{l}\text { The } 1998 \text { IECC is mandatory for jurisdictions that do not adopt } \\
\text { their own code and for state-owned and -leased facilities }\end{array}$ \\
\hline Oregon & $\begin{array}{l}\text { State-developed code that exceeds } 1995 \text { MEC is mandatory } \\
\text { statewide }\end{array}$ \\
\hline Pennsylvania & $\begin{array}{l}\text { State-developed code based on ASHRAE } 90 A-1980 \text { and } 90 B \text {. } \\
1975 \text { is mandatory statewide. }\end{array}$ \\
\hline Rhode Island & 2000 IECC \\
\hline South Carolina & 2000 IECC \\
\hline South Dakota & None. \\
\hline Tennessee & 1992 MEC \\
\hline Texas & 2000 IECC w/2001 supplement \\
\hline Utah & 2000 IECC \\
\hline Vermont & $\begin{array}{l}\text { Residential Building Energy Standards (RBES) exceeds } 95 \\
\text { MEC by } 5 \%\end{array}$ \\
\hline Virginia & $1995 \mathrm{MEC}$ \\
\hline Washington & State-developed code is mandatory statewide \\
\hline West Virginia & 2000 IECC \\
\hline Wisconsin & $\begin{array}{l}\text { State-developed code (COMM 22), which meets or exceeds } \\
1995 \text { MEC for } 1-2 \text { family dwelling (can use REScheck when } \\
\text { use of WI code is designated) Multi-family dwellings must meet } \\
\text { compliance with } 2000 \text { IECC (can use REScheck when use of } \\
2000 \text { IECC code is designated) }\end{array}$ \\
\hline Wyoming & $\begin{array}{l}\text { The ICBO Uniform Building Code, which is based on the } 1989 \\
\text { MEC, may be adopted and enforced by local jurisdictions. }\end{array}$ \\
\hline
\end{tabular}


References

Health Canada 1995. Exposure Guidelines for Residential Indoor Air Quality, A Report of the FederalProvincial Advisory Committee on Environmental and Occupational Health, Minister of Supply and Services Canada, EHD-TR-156.

Hertwich, E.G., Mateles, S.F., Pease, W.S., McKone T.E. (2001) “Human toxicity potentials for life cycle analysis and toxics release inventory risk screening," Environmental Toxicology and Chemistry 20(4):928-939.

McKone, TE 1996. "Overview of the Risk Analysis Approach and Terminology: The Merging of Science, Judgment, and Values," Food Control 7(2), 69-76.

NRC (National Research Council). 1982. Risk and Decision Making: Perspectives and Research, National Academy Press, Washington, D.C.

NRC (National Research Council). 1994. Science and Judgment in Risk Assessment, National Academy Press, Washington, D.C.

NRC (National Research Council). 1996. Understanding Risk, Informing Decisions in a Democratic Society, National Academy Press, Washington, D.C.

NRC (National Research Council). 2002. Biosolids Applied to Land: Development of Chemical and Pathogen Standards, Committee on Toxicants and Pathogens in Biosolids Applied to Land, National Academy Press, Washington D.C.

Pellizzari, E.D., T.D. Hartwell, R.L. Perritt, C.M. Sparacino, L.S. Sheldon, R.W. Whitmore, and L.A. Wallace. 1987. Comparison of indoor and outdoor residential levels of volatile organic chemicals in five U.S. geographic areas. Environ. Int. 12:619-623.

Presidential/Congressional Commission on Risk Assessment and Risk Management. 1997. Framework for Environmental Health Risk Management, Final Report, Volume 1. http://www.riskworld.com.

Seppanen, O., W.J. Fisk and M.J. Mendell. 1999. Association of ventilation rates and CO2 concentrations with health and other responses in commercial and institutional buildings, Indoor Air 9(4):226-252.

Seppanen, O., W.J. Fisk and M.J. Mendell. 2002. Ventilation rates and health. ASHRAE Journal 44(8):56-58.

Spengler, J.D., C.P. Duffy, R. Letz, T.W. Tibbets, and B.G. Ferris Jr. 1983. Nitrogen dioxide inside and outside 137 homes and implications for ambient air quality standards and health effects research. Environ. Sci. Technol. 17:164-168.

U.S. Environmental Protection Agency (EPA). 1990. Unfinished Business: A Comparative Assessment of Environmental Problems, (1987); U.S. EPA, Science Advisory Board, Reducing Risk: Setting Priorities and Strategies for Environmental Protection.

U.S. EPA (U.S. Environmental Protection Agency). 1986. The Risk Assessment Guidelines of 1986, EPA/600/8-87/045.

U.S. EPA (U.S. Environmental Protection Agency). 1996. Proposed Guidelines for Carcinogen Risk Assessment. EPA/600/P-92/003C. Fed. Regist. 61(April 23):17960-18011. [Online]. Available: http://www.epa.gov/nceawww1/raf/cra_prop.htm.

Wallace, L.A. 1993. A decade of studies of human exposure: What have we learned? Risk Anal. 13:135-139.

Wargocki P., J. Sundell, W. Bischof G. Brundrett, P.O. Fanger, F. Gyntelberg, S.O. Hanssen, P. Harrison, A. Pickering O. Seppanen P. Wouters. 2002. Ventilation and health in non-industrial indoor environments: report from a European Multidisciplinary Scientific Consensus Meeting (EUROVEN) Indoor Air 12(2):113-128. 